\title{
Relative Shocks, Relative Price Variability, and Inflation
}

THE COEXISTENCE of high inflation and low real growth has received its share of attention in the attempts to understand the U.S. economic performance of the 1970s. Analytic contributions in the imperfect information market-clearing framework have shown how uncertainty about inflation can reduce the efficiency of the price system and how relative price variability is likely to be greater when there are unanticipated changes in the price level. Such analyses, combined with the assumption that high inflation rates are also more uncertain, provide a rationalization for the view that inflation may itself be a factor explaining the poor performance of the United States and other industrial economies after 1973.

The relation between the rate of inflation and its variability was debated in Brookings Papers in 1971. In this paper I investigate a related issue: the relation between inflation and relative price variability. I discuss various explanations of a causal relation between inflation and relative price variability and provide estimates of the share of relative price variability that can be attributed to monetary and fiscal policy. ${ }^{1}$ In ex-

I am grateful to Angus Deaton, Thomas Stoker, John Taylor, and members of the Brookings panel for discussions that led to the improvement of this paper. Since presenting the paper at the Brookings panel meeting, I have benefited from reading part of David J. Stockton, "Relative Price Dispersion and Aggregate Price Movement" (Ph.D. dissertation in progress, Yale University). Donald Deere and Jeffrey Miron provided able research assistance. Financial support from the National Science Foundation and Hoover Institution is acknowledged with thanks.

1. The role of unanticipated price changes has been treated by Robert E. Lucas, Jr., "Some International Evidence on Output-Inflation Tradeoffs," American Economic Review, vol. 63 (June 1973), pp. 326-34; Robert J. Barro, "Rational Expec- 
amining the 1970s, I explore the possible special importance of supply shocks to food and energy and briefly compare performance in Japan and Germany with that in the United States. I also consider the variability of quantities rather than prices as a more direct indicator of the social welfare cost of variability.

tations and the Role of Monetary Policy," Journal of Monetary Economics, vol. 2 (January 1976), pp. 1-32; Alex Cukierman, "Relative Price Variability, Inflation, and the Allocative Efficiency of the Price System," forthcoming in Journal of Monetary Economics, and Zvi Hercowitz, "Money and the Dispersion of Relative Prices," Journal of Political Economy, vol. 89 (April 1981), pp. 328-56.

The relation between inflation and its variability was debated in Arthur M. Okun, "The Mirage of Steady Inflation," BPEA, 2:1971, pp. 485-98, and Robert J. Gordon, "Steady Anticipated Inflation: Mirage or Oasis?" BPEA, 2:1971, pp. 499-510. Okun argued, on the basis of international cross-sectional data from the 1950s and 1960s, that higher average inflation rates are also more variable inflation rates; Gordon showed that the relation was much weaker for the 1960s. Subsequent research, for instance that by John B. Taylor, shows that the experience of the 1970s conforms to Okun's findings. See his paper in Karl Brunner and Allan H. Meltzer, eds., "On the Relation between the Variability of Inflation and the Average Inflation Rate," in The Costs and Consequences of Inflation, Carnegie-Rochester Conference Series on Public Policy, vol. 15 (Amsterdam: North-Holland, 1981), pp. 57-85.

Because variability and uncertainty are not the same, the question remains whether the more variable inflation of the 1970s was also more uncertain than the inflation of the previous two decades. I have investigated this question and do not find uncertainty about the inflation rate to be significantly greater in the 1970s than earlier. See Stanley Fischer, in Brunner and Meltzer, eds., "Towards an Understanding of the Costs of Inflation: II," in The Costs and Consequences of Inflation, pp. $5-41$.

Inflation and relative price variability have been discussed in many other papers, including Daniel R. Vining, Jr., and Thomas C. Elwertowski, "The Relationship between Relative Prices and the General Price Level," American Economic Review, vol. 66 (September 1976), pp. 699-708; Richard W. Parks, "Inflation and Relative Price Variability," Journal of Political Economy, vol. 86 (February 1978), pp. 7995; Dwight Jaffee and Ephraim Kleiman, "The Welfare Implications of Uneven Inflation," in Erik Lundberg, ed., Inflation Theory and Anti-Inflation Policy (London: Macmillan, 1977), pp. 285-307; Mario I. Blejer and Leonardo Leiderman, "On the Real Effects of Inflation and Relative-Price Variability: Some Empirical Evidence," Review of Economics and Statistics, vol. 62 (November 1980), pp. 539-44; and John Taylor, "On the Relation between the Variability of Inflation and the Average Inflation Rate." I take up this subject in "Relative Price Variability and Inflation in the United States and Germany," forthcoming in European Economic Review.

Two classics from the 1920 s discuss the relation between inflation and relative price variability: Frank D. Graham, Exchange, Prices and Production in HyperInflation: Germany, 1920-1923 (Princeton University Press, 1930), chap. 7, pp. 174-208; and Frederick C. Mills, The Behavior of Prices (National Bureau of Economic Research, 1927), pp. 251-86. 


\section{Relations between Inflation and Relative Price Variability}

Theories linking inflation and relative price variability tend to fall into one of two categories. The first type of theory concentrates on market behavior; it takes either inflation or relative price variability as exogenous and shows how the other phenomenon may result under certain assumptions about the operation of markets. The second type of theory focuses on the exogenous factors that affect the economy and aims to show how these may, singly or in combination, generate both inflation and relative price variability.

Much recent empirical work on the relation between relative price variability and inflation has used the market-clearing framework with rational expectations and misperceptions. ${ }^{2}$ This approach does not fall neatly into either of the categories discussed above. For although it hypothesizes that shocks cause both inflation and relative price variability, variability logically, but not temporally, follows inflation. Relative price variability occurs only through misperception of inflation, but the reverse is not true. I discuss this theory first, and then go on to consider two theories of market behavior and three views of the economy that emphasize exogenous shocks. Thus altogether I discuss six approaches to examining the relation between inflation and relative price variability.

In the first approach-rational expectations with market clearing and misperceptions-unanticipated changes in the price level and increased relative price variability are both the result of unanticipated changes in the money stock. ${ }^{3}$ A fully perceived change in the money stock has no effect on relative prices. A misperceived change in the money stock leads to changes in prices in individual markets that are viewed by market participants as, in part, changes in relative prices. If demand and supply elasticities in individual markets differ, these believed changes in relative prices result in changes in actual relative prices. Because there has been no change in real economic conditions, and assuming the full information

2. The theory and its implications for the links between relative price variability and unanticipated changes in the price level are set out in Barro, "Rational Expectations."

3. As a matter of logic, unanticipated shifts in money demand have the same effects as those attributed here to unanticipated money supply. Empirically, however, the emphasis has been on money supply. 
equilibrium is efficient, the changes in relative prices cause misallocations of resources.

In the simplest versions of this approach, anticipated changes in the money stock have no effects on relative prices, so that anticipated inflation should not be associated with greater relative price variability. In more sophisticated versions of the theory, anticipated inflation may be nonneutral, affecting real interest rates and thus relative prices. But the emphasis is clearly on the role of unanticipated changes in the money stock and the inflation rate.

Increased relative price variability is associated with unanticipated changes in the price level in either direction rather than with unanticipated inflation per se. Finally, unanticipated changes in the money stock could affect relative prices for several periods once the initial misallocations have been induced, either because information moves slowly or because the initial misallocations are embodied in capital stocks in different industries.

Theories that build on "menu costs" provide a second approach to the relation between higher variability of relative prices and higher inflation. ${ }^{4}$ Such theories take the inflation rate as exogenous. It is assumed that there is a lump-sum cost of changing prices, and that prices therefore change only at discrete intervals. When the inflation rate rises, prices are changed more frequently, but under reasonable assumptions, not often enough to maintain the previous dispersion of relative prices, which now widens. The assumption is that price changes are not temporally coordinated but rather occur randomly in time. The dispersion of relative prices does not necessarily increase in such a model if, for example, wage adjustments through a cost-of-living clause become more frequent as the inflation rate increases.

The menu-cost approach relates increased relative price variability to inflation itself, rather than to unanticipated inflation or the change in the inflation rate. The theory also predicts that increased price variability accompanies general deflation.

4. Michael Mussa, "The Welfare Cost of Inflation and the Role of Money as a Unit of Account," Journal of Money, Credit and Banking, vol. 9 (May 1977), pp. 276-86; Eytan Sheshinski and Yoram Weiss, "Inflation and the Costs of Price Adjustment," Review of Economic Studies, vol. 64 (April 1977), pp. 287-303; and Julio Rotemberg, "Fixed Cost of Price Adjustment and the Impact of Inflation" (Massachusetts Institute of Technology, Sloan School of Management, 1980). 
A third approach takes relative price variability as exogenous and uses an assumed asymmetric response of prices to disturbances to derive a positive association between relative price variability and the rate of inflation. For instance, suppose that prices are inflexible downward, that in the absence of relative disturbances the price level remains unchanged from last period's level, and that individual markets are affected by relative disturbances. ${ }^{5}$ In markets in which excess demand has increased, price rises; if there is excess supply, actual price does not fall. The result is that the larger the variability of relative disturbances, the higher the average inflation rate.

An important question about asymmetric price adjustment is whether the asymmetry is around zero or rather some conventional notion of the warranted inflation rate. If downward price inflexibility is meant literally, in the sense that prices may rise but not fall, the association between relative price variability and the inflation rate disappears as the inflation rate rises. If, instead, prices rise more easily than they fall about some accepted core or expected rate of inflation, the association between higher than average or expected inflation and relative price variability continues to apply at high rates of inflation.

Before proceeding to a more detailed discussion of the remaining approaches, which direct attention to exogenous factors that have both relative and aggregate effects, it is useful briefly to discuss the meaning of relative price disturbances. A pure relative disturbance is a change in supply or demand conditions that leaves appropriately defined aggregate real output and the price level unchanged. There are two notions of such disturbances. First, the disturbances in different industries may be mutually offsetting, as with shifts in demand between goods. Second, industrylevel disturbances may be considered as in some sense averaging out to zero relative to the aggregate economy.

Disturbances that are viewed as primarily relative shocks may also have aggregate consequences. Thus the oil shock not only increased the relative price of oil but also reduced aggregate supply. An increase in the propensity to consume is a relative shift in the sense that it reflects an increased demand for current goods at the expense of future goods, but also increases aggregate demand.

5. Such a model is the goods market equivalent of the labor market model described in James Tobin, "Inflation and Unemployment," American Economic Review, vol. 62 (March 1972), pp. 1-18. 
The fourth approach linking inflation and relative price variability asserts that many disturbances that affect relative prices also have macroeconomic consequences. This is particularly true in the case of major supply shocks, which typically occur in specific industries. Further, because of differential speeds of adjustment in different markets, even disturbances that are ultimately neutral in their price-level effects can in the short run affect the aggregate price level. ${ }^{6}$ If short-run supply elasticity is smaller in one industry than in another, a demand shift between the industries does not affect prices in the two industries equally, and therefore results in a change in the aggregate price level. Changes in the price level relative to trend in either direction are associated with changes in the variability of relative prices.

The fifth approach suggests that government macroeconomic policy, rather than nonpolicy disturbances, may cause both inflation and relative price variability. Increases in government spending are likely to both increase the inflation rate and change the composition of final demand and thus relative prices. If inflation is nonneutral, anticipated and actual changes in the inflation rate will change the real interest rate and affect the allocation of goods and relative prices-for instance between durables and nondurables. In this view, changes in the inflation rate rather than the level of the inflation rate are associated with increased relative price variability.

In the sixth approach, the relation between inflation and relative price variability results from accommodating macroeconomic policy. The effects on real output of real disturbances that both increase relative price variability and tend to produce unemployment, such as the oil price shock, can be moderated by accommodating policy, which reduces the decline in output at the expense of more inflation. ${ }^{7}$ Similarly, if price response is asymmetric, the level of output is low when relative disturbances have a large variance because output is low in the industries in which prices should have fallen. Accommodating policy appears attractive here, too. Indeed, asymmetric price response might be the result of accommodating policy. In either case, a shock that increases the variability of relative

6. David Stockton develops this approach and implements it empirically in "Relative Price Dispersion."

7. John Taylor sets out a model of this type in "On the Relation." 
Table 1. Summary of Approaches Linking the Inflation Rate and Relative Price Variability

\begin{tabular}{|c|c|c|c|}
\hline Approach & $\begin{array}{l}\text { Exogenous } \\
\text { factors }\end{array}$ & $\begin{array}{l}\text { Function of inflation } \\
\text { associated with } \\
\text { relative price } \\
\text { variability }\end{array}$ & $\begin{array}{l}\text { Welfare } \\
\text { implications }\end{array}$ \\
\hline $\begin{array}{l}\text { 1. Market clearing } \\
\text { with imperfect } \\
\text { information }\end{array}$ & $\begin{array}{l}\text { Policy } \\
\text { disturbances }\end{array}$ & $\begin{array}{l}\text { Unanticipated } \\
\text { inflation or deflation }\end{array}$ & $\begin{array}{l}\text { Misperceived aggregate } \\
\text { disturbances produce } \\
\text { resource misallocations }\end{array}$ \\
\hline 2. Menu costs & $\begin{array}{l}\text { Inflation } \\
\text { rate }\end{array}$ & Inflation or deflation & $\begin{array}{l}\text { Inflation or deflation } \\
\text { creates resource } \\
\text { misallocations and } \\
\text { generates unnecessary } \\
\text { transaction costs }\end{array}$ \\
\hline $\begin{array}{l}\text { 3. Asymmetric } \\
\text { price response }\end{array}$ & $\begin{array}{l}\text { Relative } \\
\text { disturbances }\end{array}$ & $\begin{array}{l}\text { Either inflation rate } \\
\text { or inflation in excess } \\
\text { of base rate }\end{array}$ & $\begin{array}{l}\text { Price inflexibility } \\
\text { leads to resource } \\
\text { misallocations: } \\
\text { there is too little } \\
\text { relative price } \\
\text { variability }\end{array}$ \\
\hline $\begin{array}{l}\text { 4. Relative shocks } \\
\text { same as aggre- } \\
\text { gate shocks }\end{array}$ & $\begin{array}{l}\text { Real } \\
\text { disturbances }\end{array}$ & $\begin{array}{l}\text { Deviations of inflation } \\
\text { from underlying rate } \\
\text { in either direction } \\
\text { depending on type } \\
\text { of shock }\end{array}$ & $\begin{array}{l}\text { Relative prices } \\
\text { should vary for } \\
\text { efficient allocation }\end{array}$ \\
\hline $\begin{array}{l}\text { 5. Allocative effects } \\
\text { of macro policy }\end{array}$ & $\begin{array}{l}\text { Changes in } \\
\text { policy }\end{array}$ & $\begin{array}{l}\text { Changes in inflation } \\
\text { rate }\end{array}$ & $\begin{array}{l}\text { Given the changes in } \\
\text { policy, relative prices } \\
\text { should vary for efficient } \\
\text { allocation }\end{array}$ \\
\hline $\begin{array}{l}\text { 6. Endogenous } \\
\text { policy }\end{array}$ & $\begin{array}{l}\text { Real } \\
\text { disturbances }\end{array}$ & Same as 3 & $\begin{array}{l}\text { Policy may offset } \\
\text { welfare loss associated } \\
\text { with relative shocks } \\
\text { by making appropriate } \\
\text { price adjustments } \\
\text { possible }\end{array}$ \\
\hline
\end{tabular}

prices might be followed by a policy reaction that increases the inflation rate.

The implications of the six approaches for the association between inflation and the variability of relative prices are outlined in table 1 . The various theories do not have sharply different implications for the association between inflation and relative price variability. The fourth and 
fifth approaches both imply that relative price variability is associated with the absolute value of changes in the inflation rate. The second, third, and sixth suggest that higher relative price variability is associated with higher inflation rather than with the change in the inflation rate. The first approach seems to be distinct from the others, but because in practice unanticipated inflation is not easily distinguishable from the change in the inflation rate, the distinction between the first, fourth, and fifth approaches is not easy to make. The second and third approaches differ in their implications for periods of deflation; the third predicts that deflation is unlikely; the second predicts an increase in the variability of relative prices.

Although the approaches do not differ much in their implications for the association between relative price variability and inflation, they do differ in the implied welfare significance of the association. According to the first three approaches, the association signifies an inefficient allocation of resources. While the first implies the variability is excessive, the third suggests the inefficiency arises from too little relative price variability. In the second, the menu-cost approach, the variation is excessive because it could be reduced by a lower inflation rate. The greater relative price variability associated with inflation according to the fourth and fifth approaches is a reflection of the efficient allocation of resources given policy choices. To complicate matters, the approaches are not mutually exclusive. Certainly all the theories except the third could be simultaneously valid.

An important conclusion follows directly from the preceding discussion. Because disturbances sometimes originate with policy and occasionally with nonpolicy shocks, and because the disturbances often may be either microeconomic or macroeconomic, there is not likely to be a single stable relation between relative price variability and the inflation rate, or its absolute value, or any other characteristic of the time series of inflation. The relation will differ depending on the disturbances that predominate in particular periods.

In this paper I demonstrate that the relation between inflation and relative price variability observed in recent U.S. data is predominantly a result of the food and energy price shocks of the 1970s. But at other times and places-for example, in hyperinflations-monetary disturbances might well be the primary source of both inflation and relative price variability. Or, as at the outset and end of wars, changes in fiscal policy may 
have both allocative and macroeconomic effects and may cause both inflation and increased relative price variability.

\section{Empirical Relations between Inflation and Relative Price Variability}

This section presents data and regressions on relative price variability and the inflation rate. Figure 1 is based on the consumption price deflator for the period from 1930 to 1980 . The inflation rate is the rate of increase of the consumption deflator. ${ }^{8}$ The variance of relative prices shown in the figure is the variance of the rates of change of the individual components of the consumption deflator. It is defined by

$$
V A R N_{t}=\sum_{1}^{N} w_{i t}\left(\pi_{i t}-\pi_{t}\right)^{2}
$$

where $\quad w_{i t}=$ weight of the $i$ th component of the deflator

$\pi_{i t}=$ rate of increase of the $i$ th component of the deflator

$\pi_{t}=$ overall inflation rate for the period. ${ }^{9}$

The appendix shows the relevant components of the deflator for alternative indexes made up of different numbers of commodities.

\section{MEASURING PRICE VARIABILITY}

The price variability measure defined by equation 1 and used in the remainder of this paper is standard. ${ }^{10}$ Nonetheless, there are two serious questions about the measure.

The first question is whether price variability should be measured by the variance of the individual inflation rates of components of the index

8. For all except one series in the paper the inflation rate is defined as $\left(\ln P_{t}-\ln P_{t-1}\right)$. The exception is pointed out below.

9. The data from 1930 to 1975 in figure 1 are calculated by Richard W. Parks in "Inflation and Relative Price Variability." Parks uses annual inflation rates. The weights are averages of the shares of that component of the deflator in consumption for the two periods between which the inflation rate is calculated. The Parks data from 1960 on were recalculated to reflect data revisions and extended through 1980. The variability measure is based on a twelve-component breakdown of consumption expenditures (see the appendix).

10. It is used, for example, in Richard Parks, "Inflation and Relative Price Variability"; John Taylor, "On the Relation"; and Mario Blejer and Leonardo Leiderman, "On the Real Effects." 
Figure 1. Inflation and the Variability of Relative Prices, Personal Consumption Expenditure Deflator, 1930-80

Inflation rate

(percent per year)
Variance of relative price change (percent per year, squared)

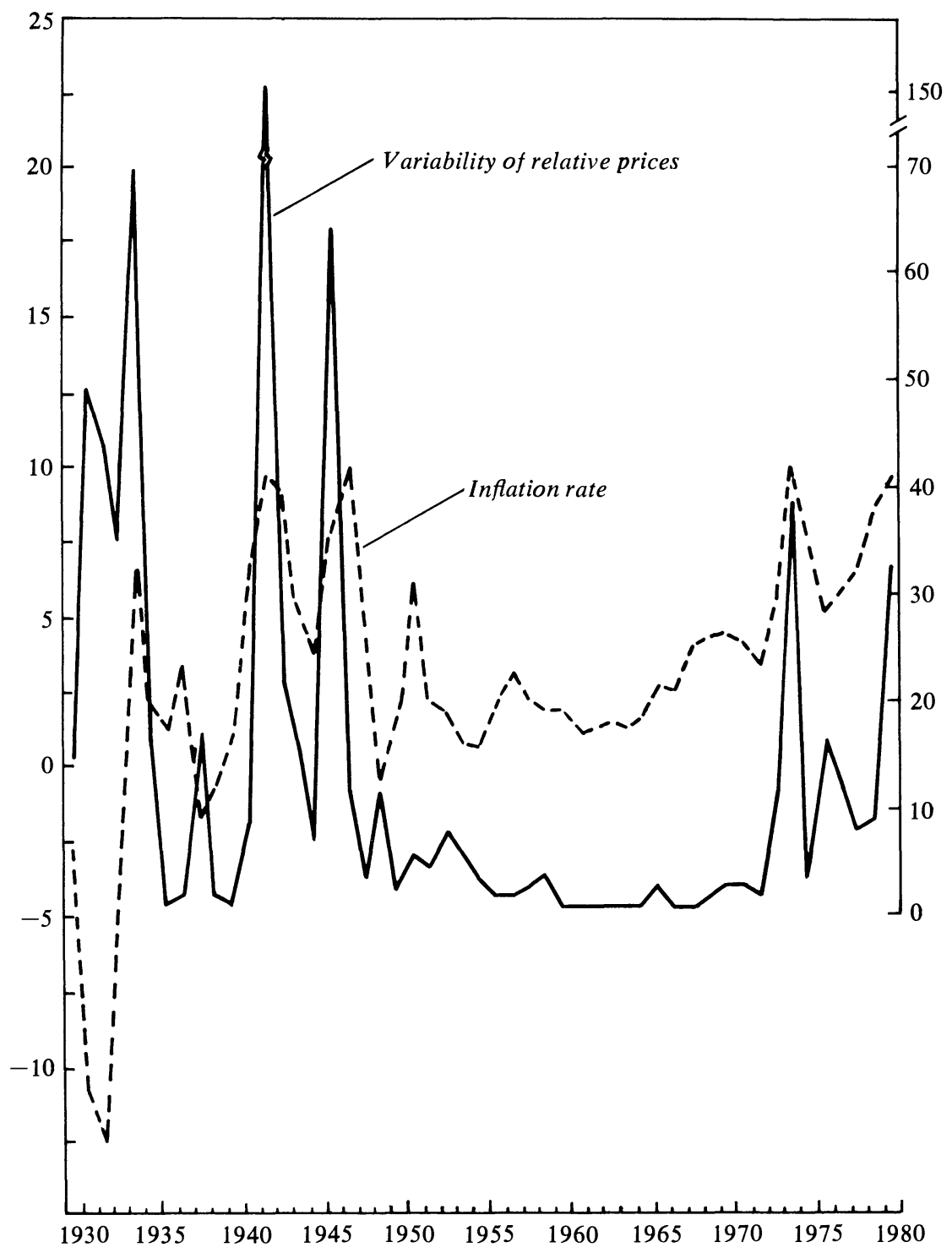

Source: Data from 1930 to 1975 are from Richard W. Parks, "Inflation and Relative Price Variability," Journal of Political Economy, vol. 86 (February 1978), p. 85. The Parks data have been revised from 1960 and updated to 1980 using the Citibank Economic Database. 
about the average inflation rate, as done here, or whether it should be measured by variations of individual price levels around some appropriate path for the relative prices of the individual components. Ideally it would be best to work with deviations of relative prices from their appropriate levels. Without a general equilibrium, maximizing model of the economy, there is no way of knowing what those relative prices should be.

The measure of relative price variability defined by 1 cannot distinguish between the changes in relative prices that are appropriate for the optimal allocation of resources and those that are mistakes. Sometimes when there are different rates of change of prices of goods, that is appropriate; sometimes it is not. The measure doubly penalizes a change in a relative price that is subsequently reversed. For instance, if the inflation rate for one variable is initially less than average and later, in compensation, is above average, relative price variability as measured here is higher in each period. If, on the other hand, there is a permanent decline in the relative price of a good, that shows up only once in the variability measure. To the extent that inappropriate changes in relative prices can be equated with changes that are later reversed, the measure I use properly emphasizes such price changes more than permanent changes.

The second question concerns the degree of aggregation. The measures of variability used here are highly aggregated. ${ }^{11}$ It would appear to be better to use data at as low a level of aggregation as possible. If the misallocations associated with unexpected inflation in market clearing with misperceptions (the first approach in table 1) arise from excessive search, it is possible that search would take place only in response to believed differences in prices of very similar goods. In this case, the level of aggregation I adopt would not be appropriate. Indeed, if excessive search is believed to be the mechanism through which monetary disturbances produce misallocations of resources, it would be desirable to collect time series of the dispersion of prices of the same good. ${ }^{12}$ Such data are not currently available. Thus this paper does not provide a strong test of misallocation of resources at the level of individual markets.

11. Data that are less aggregated are used by Daniel Vining and Thomas Elwertowski, "The Relationship," and by David Stockton, "Relative Price Dispersion."

12. John W. Pratt, David A. Wise, and Richard Zeckhauser found prices of standardized commodities varying widely at the same time within the same geographical area. See their "Price Differences in Almost Competitive Markets," Quarterly Journal of Economics, vol. 63 (May 1979), pp. 189-211. 


\section{AN OVERVIEW OF PRICE VARIABILITY}

The time series in figure 1 show substantial peaks in the variance of relative prices in 1931, 1934, 1942, 1946, 1974, and 1980. The first peak is associated with sharp deflation; the later peaks with inflation. A closer look shows small peaks in the variability of relative prices associated with the deflation of 1938 and 1949. The most notable feature of the figure, besides the peaks, is the low level of the variability of relative prices in the 1960s. The higher variability of the 1970 s does not come close to matching that of the Great Depression.

Figure 1 suggests that the first, fourth, and fifth approaches of table 1 may be useful in explaining links between inflation and relative price variability. The peak of relative price variability in 1931 is associated with a monetary disturbance that produced unanticipated deflation, as implied by the first approach. The 1942 and 1946 peaks in the variability of relative prices are related to increases and decreases in government spending associated with mobilization and demobilization, an example of the fifth approach. The peaks in relative price variability in 1974 and 1980 are associated with the two energy shocks, an example of the fourth approach. Explanations of the historical record that rely on the other approaches cannot be ruled out, however. For example, the 1931 episode might be explained by the menu costs of the required deflation.

The dominance of the energy and food shocks in the 1970s is clear from figure 2 , in which a series called $V A R 8$, which excludes those prices, is presented along with $V A R 11$, a series that includes them. Both series measure variance of relative prices, as defined in equation 1 , calculated from eight and eleven components of the consumption deflator, respectively. The components included in VAR8 and VAR11 are specified in the appendix. It is striking that $V A R 8$ is lower in the 1970 s than it was at the end of the $1950 \mathrm{~s}^{13}$

Figure 3 contains a measure of the variability of prices calculated by Frederick C. Mills in his classic work. ${ }^{14}$ Mills examines the behavior of

13. The higher level of $V A R 8$ compared with $V A R 11$ from 1954 to 1956 results from high variability in the price of automobiles. These obviously have a larger weight in $V A R 8$ than in $V A R 11$.

14. Frederick C. Mills, The Behavior of Prices. The data are taken from the appendix, table 26, pp. 583-84, columns 3 and 6. Mills' standard deviations of relative prices are squared to produce the variances shown in figure 3. Mills' inflation series is calculated from rates of inflation defined as $\left(P_{t}-P_{t-1}\right) / P_{t-1}$. 
Figure 2. Variability of Relative Prices, including ( $V A R 11)$ and excluding (VAR8) Energy and Food Prices, Personal Consumption Expenditure Deflator, 1947-80 ${ }^{a}$

Variance of relative price change (percent per quarter, squared)

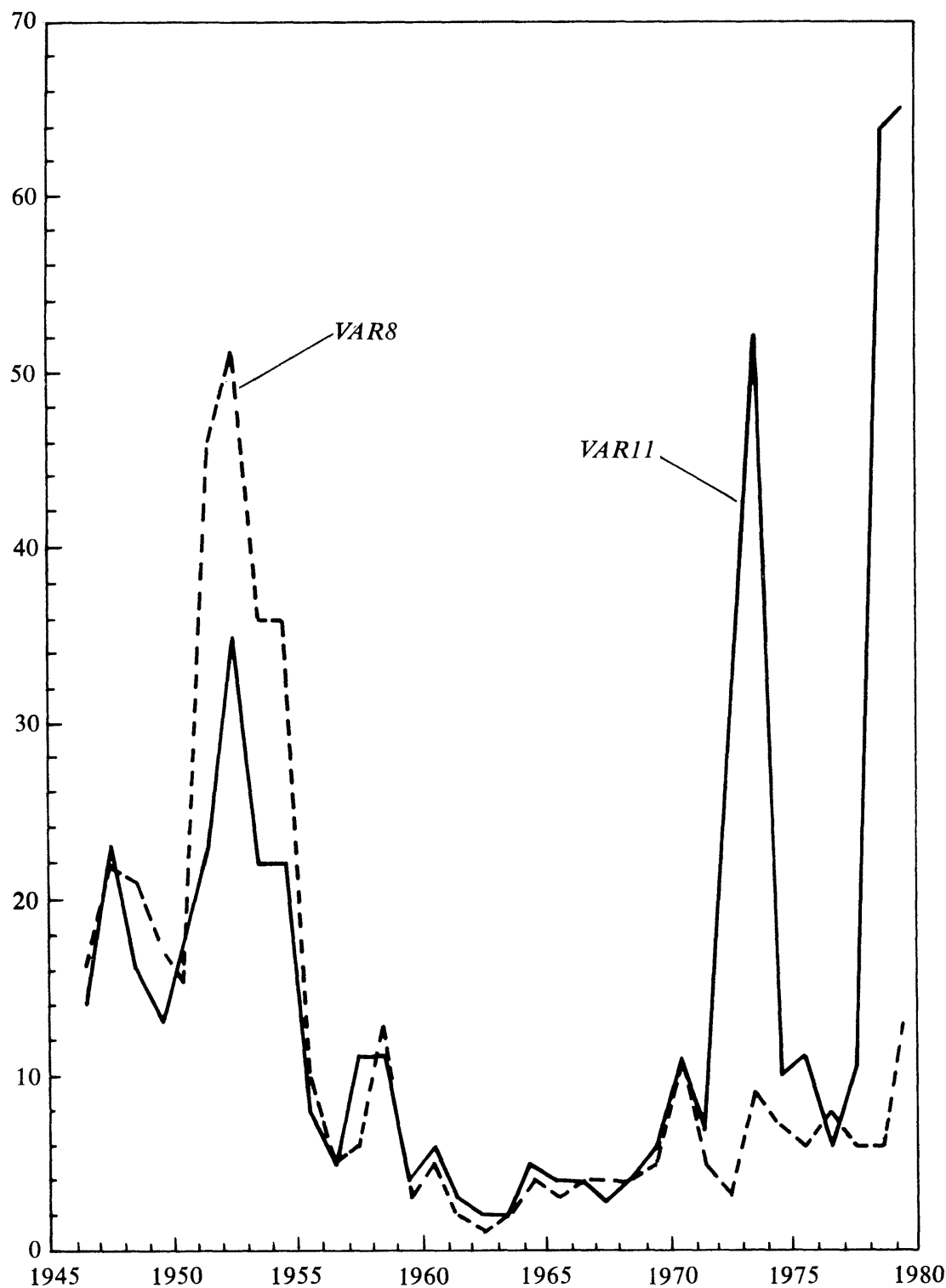

Source: Citibank Economic Database.

a. The eight and eleven components of the two variables are specified in the appendix. The $V A R$ measures are calculated for each quarter as in equation 1, based on quarter-to-quarter inflation at quarterly rates. Data are averages of the four quarterly variances computed each year for each series. 
Figure 3. Inflation and Variability of Wholesale Prices, 1891-1926

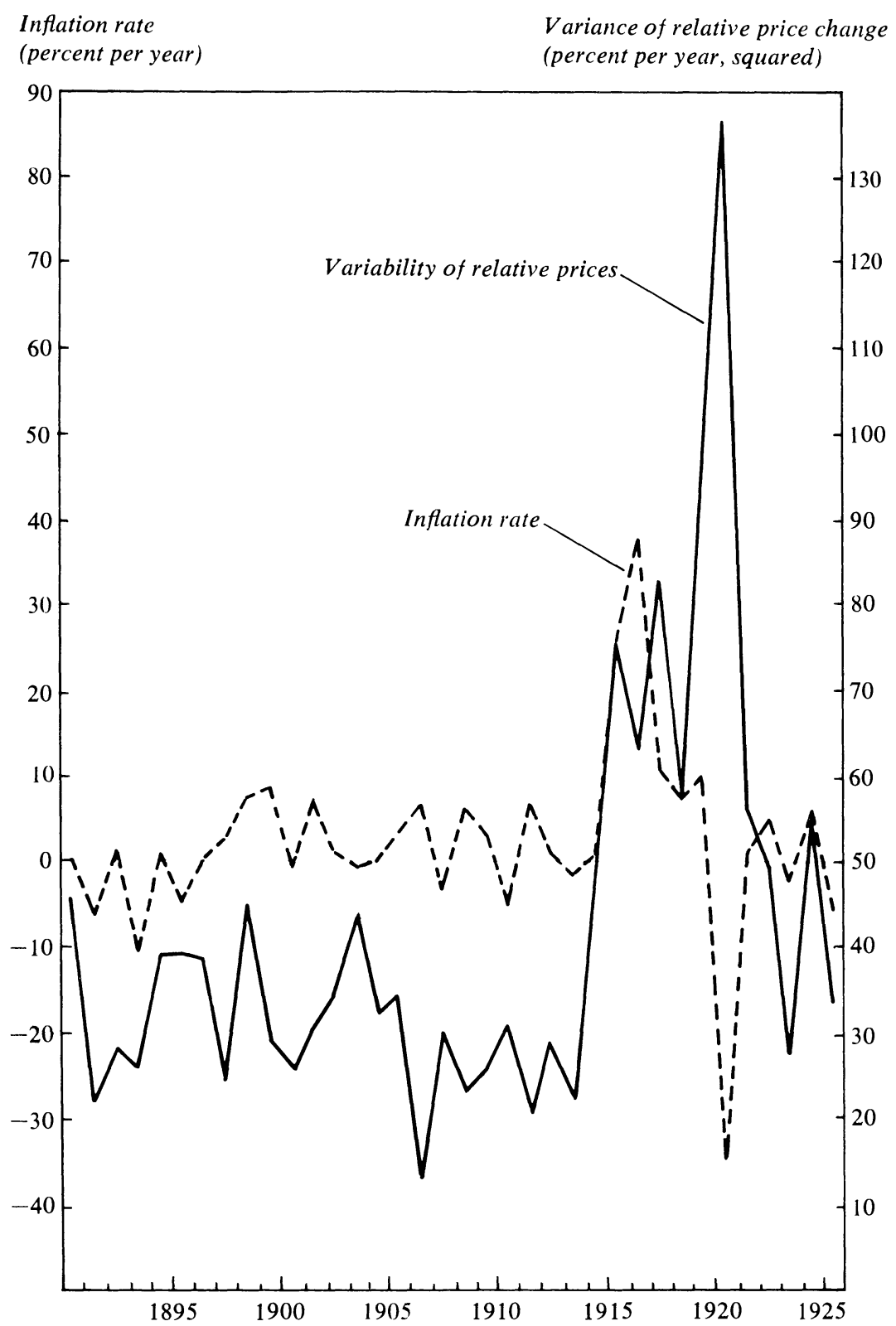

Source: Frederick C. Mills, The Behavior of Prices (National Bureau of Economic Research, 1927), table 26 , pp. 583-84. 
wholesale prices, with the index containing between 195 and 391 prices, depending on the year. Between 1913 and 1914 the number of goods in the index approximately doubled. Both the rapid inflation of 1917 and the rapid deflation of 1921 are associated with high variability of relative prices. The former is another example of a macroeconomic shock that changes the composition of demand. Mills argues that the variability of relative prices was most closely correlated with the absolute value of the change in the inflation rate. ${ }^{15}$ It is interesting to note that most of Mills' charts and tables relate the variability of relative prices to the price level rather than its rate of change.

\section{REGRESSIONS LINKING RELATIVE PRICE \\ VARIABILITY AND INFLATION}

The data presented in figures 1 to 3 make it clear that there is no single source of the correlation between relative price variability and inflation. Table 1 suggests that, depending on the source of disturbances, relative price variability might be associated with the inflation rate itself, the absolute value of the inflation rate, changes in the inflation rate, or unanticipated inflation or deflation. It is thus possible that regressions can discriminate among the approaches set out in table 1.

Tables 2 and 3 present regressions linking measures of relative price variability to the inflation rate, to changes in that rate, and to its decomposition into expected and unexpected components. Expected inflation is generated as the prediction from a fourth-order autoregression, with unexpected inflation then estimated as the difference between expected and actual inflation in each period. Three sets of data are used: the Parks annual data based on a twelve-variable decomposition of the deflator for personal consumption expenditure, giving $V A R 12$; an eleven-variable decomposition of that deflator on a quarterly basis corresponding to variability measure VAR11; and an eight-variable decomposition of the quarterly PCE deflator that excludes the prices of energy and food, giving

15. Mills did not use multiple regressions. Had he done so, and run a regression with the variability of relative prices as the dependent variable, he would have found both the change in the inflation rate and its absolute value entering with statistically significant coefficients. The coefficients indicate an asymmetric response to changes in the inflation rate, with variability rising substantially more when the inflation rate falls than when it rises. 


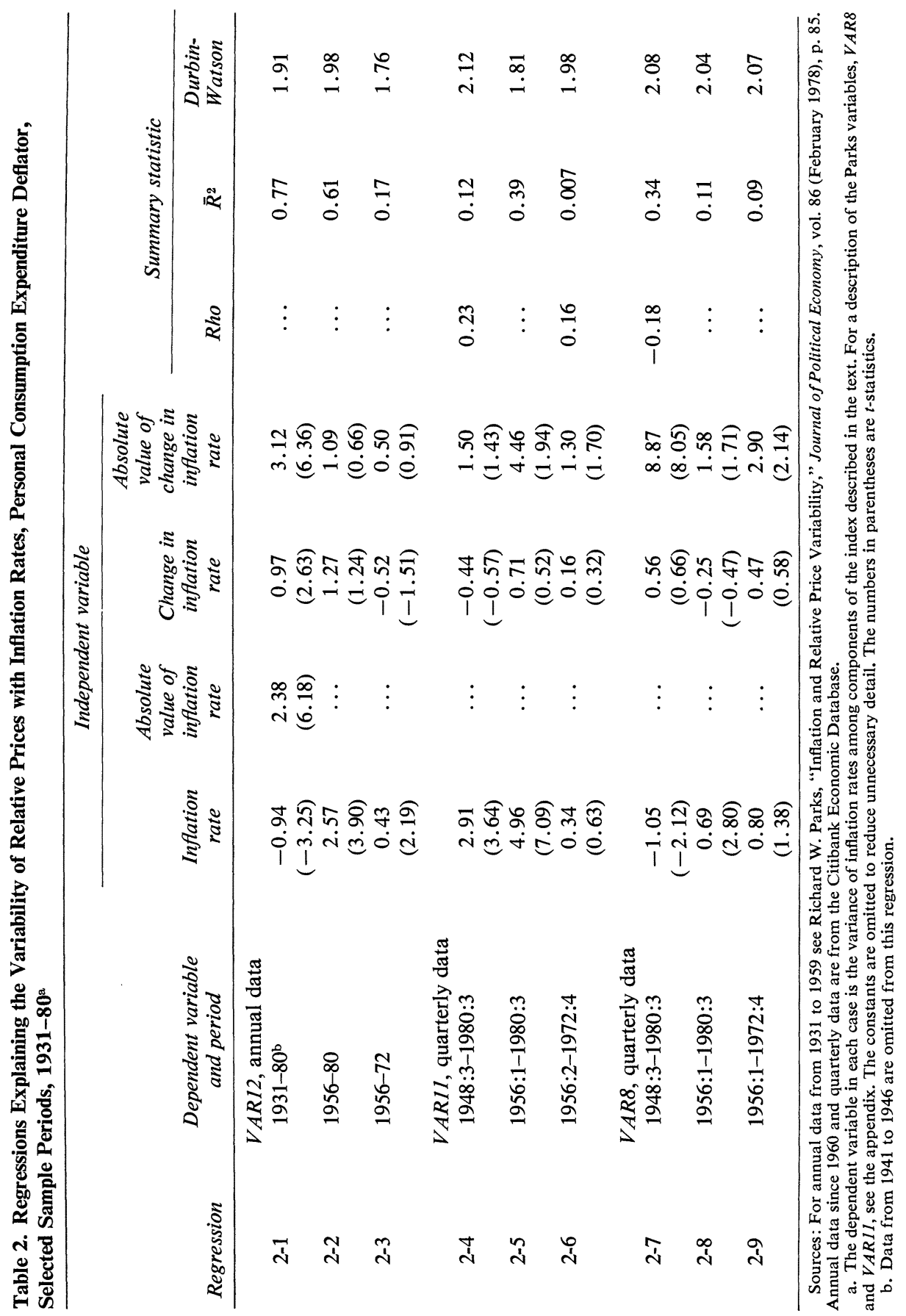




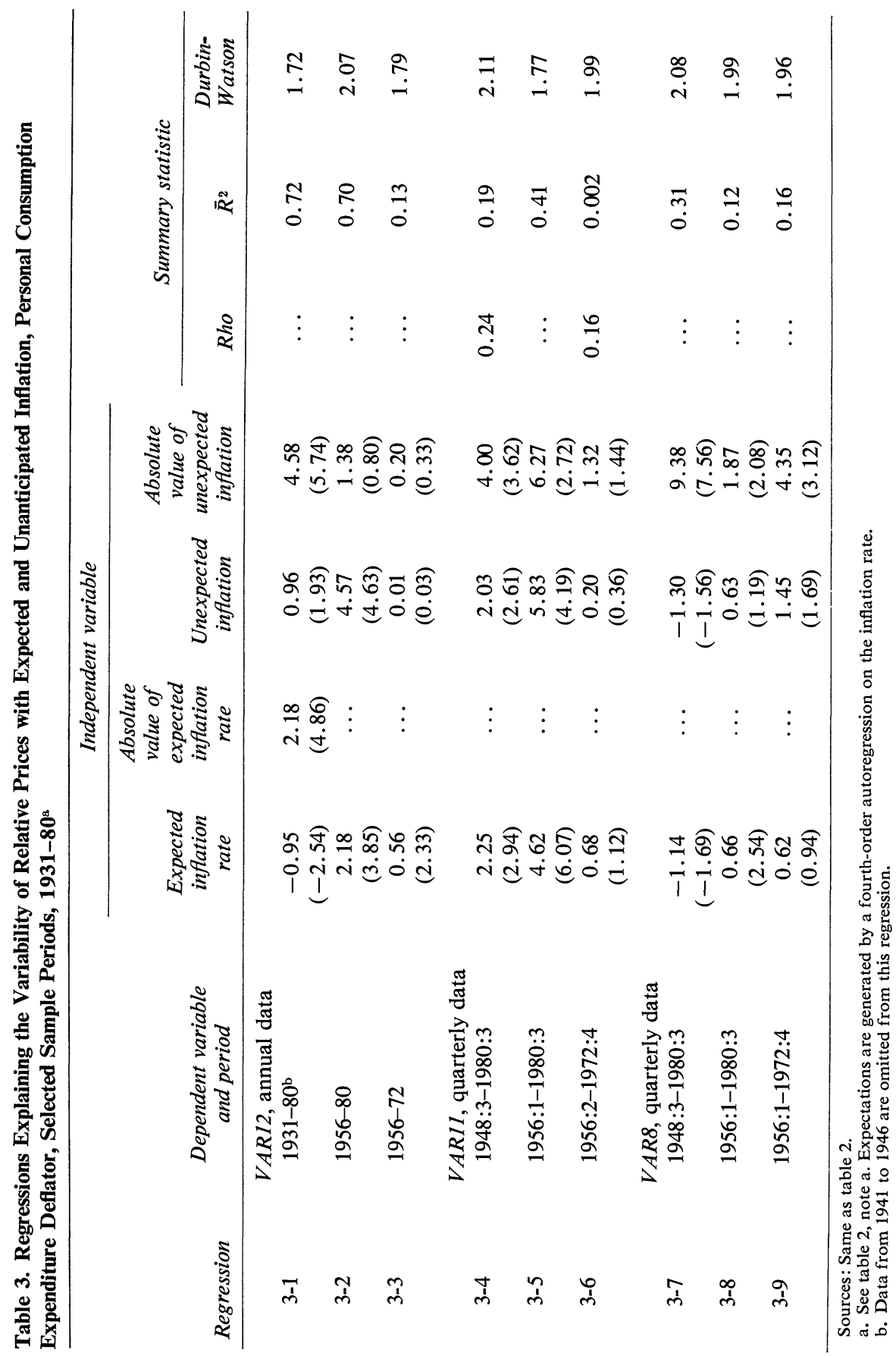


variability measure $V A R 8 .{ }^{16}$ The inflation rate in each case corresponds to the index with the same number of commodities as the variability measure. ${ }^{17}$

The regressions in table 3 could be formulated with the actual and unexpected (actual and absolute value) rates of inflation as the right-hand variables. In that case, the coefficient on the actual rate of inflation would be the same as that on the expected rate of inflation in the present representation, as would be the standard error. ${ }^{18}$

A number of features of the regression results are worth noting. First, regression 2-1 shows that over the longest sample period, variability of relative prices is significantly associated with both inflation and deflation and with changes in the inflation rate in either direction. Thus each of the last five approaches in table 1 is consistent with the results of table 2.

Second, the most persistent relation in the post-World War II data is that between variability and the actual inflation rate. The relation is generally positive and is strongest for the $1956-80$ period. However, it is evident from the contrasts between results for 1956-80 and 1956-72 that the strength of the 1956-80 relation derives from the addition of the post-1972 data.

Third, the formulations using expected and unexpected inflation and those using changes in the inflation rate are empirically similar. Given the generation of the expected rate of inflation from a fourth-order autoregression, there is little difference between the change in the inflation rate and unexpected inflation. ${ }^{19}$

16. Calculations were also made using VAR16 (the components of which are also shown in the appendix), but results for this index are similar to those for VAR11.

17. The coefficients of lagged terms added to the regressions of tables 2 and 3 are generally not statistically significant.

18. With the alternative formulation, the coefficient on the unanticipated rate of inflation, $\pi^{u}$, would be equal to the reported coefficient on $\pi^{u}$ minus the reported coefficient on $\pi^{e}$, the expected rate of inflation. The standard error of $\pi^{u}$ in this case cannot be calculated without information about the covariance of the coefficient estimates.

19. In Richard Parks' "Inflation and Relative Price Variability" the optimal predictor of the inflation rate for the 1930-75 sample period is the current inflation rate. There is no difference between unanticipated inflation and the change in the inflation rate in the regressions presented in his paper. From 1956:1 to $1980: 3$ the correlation between the absolute value of unanticipated inflation and the absolute value of the change in the inflation rate is 0.92 for the eleven-component inflation measure used in this paper and 0.95 for the eight-component measure. 
The significance of the expected rate of inflation in the regressions of table 3 rules out the view that anticipated inflation is neutral. This view is associated with the market-clearing, rational expectations approach, but is by no means an essential implication of that approach. If an inflationary shock takes time to have its effect on the economy, anticipated inflation could well be associated with increased relative price variability. The relation is also consistent with the menu-cost approach and with that of asymmetric price response.

Fourth, the presence of nonzero coefficients on either the change in the inflation rate (in table 2) or unanticipated inflation (in table 3 ) means that variability responds to changes in the inflation rate or to unanticipated inflation asymmetrically. Where the coefficients in question are positive, as in 2-1 and several equations in table 3, the implication is that variability rises more when unanticipated inflation (or the change in the inflation rate) is positive than when it is negative. This is consistent with the view that prices respond asymmetrically around some inflation rate set on the basis of recent experience, as in the third approach in table 1.

Fifth, it is evident from the contrasts between the regression results for different periods that there is no simple stable relation between relative price variability and inflation. The hypothesis of structural stability can be rejected for the coefficients in regressions 2-5 and 2-6 and in 3-5 and 3-6. This presumably is because the factors responsible for relative price variability and inflation differ from period to period..$^{20}$ The approaches outlined in table 1 suggest many possibilities, including: relative price disturbances and the variability of relative prices are exogenous and may cause inflation without any policy response (if price response is asymmetric); relative price variability is exogenous and may induce changes in policy that lead to inflation; changes in policy are exogenous and may produce both inflation and relative price variability; and changes in both the price level and variability may be the result of the same, nonpolicy, shock.

\section{GRANGER CAUSALITY TESTS}

As noted above, theories relating inflation to relative price variability view either aggregate demand policies or changes in relative prices as

20. The hypothesis of structural stability is not rejected for regressions 2-8 and 2-9 or for 3-8 and 3-9, all of which exclude food and energy. This suggests that disturbances to energy and food prices are responsible for the shift reflected in the temporal instability of the $V A R 11$ regressions. 
exogenous. The third, fourth, and sixth approaches in table 1 all give an independent role for relative price shocks as a source of both relative price variability and inflation.

The data and regressions presented thus far give the strong impression that any of the approaches outlined in table 1 are consistent with the empirical associations observed between inflation and relative price variability. They thus do not discriminate between those three approaches, which suggest that aggregate demand policies that produce inflation also produce relative price variability, and those approaches that suggest relative price disturbances are the main source of the relation.

If relative price disturbances are the main source, it might be expected that changes in relative prices will occur before the subsequent inflationary impacts. This will be true particularly if the source of the inflation is accommodating policy responses. Tests of Granger causation, which means essentially "temporal precedence," make it possible to examine whether there is a consistent lead or lag relation between inflation and relative price variability. ${ }^{21}$ Variable $x$ is said to "Granger cause" variable $y$ if changes in $x$ occur before changes in $y$.

Granger causation is a controversial notion because it uses the word "cause." In the context of relative price variability and inflation, Granger causality tests indicate whether changes in relative prices typically precede changes in the inflation rate or vice versa. Thus if changes in relative prices precede changes in the inflation rate, relative price variability Granger causes inflation; similarly, if changes in the inflation rate precede changes in relative price variability, inflation Granger causes relative price variability.

There are three difficulties with this post hoc ergo propter hoc reasoning. First, each variable may be reacting to a common third variable, but with different lags. Second, the test cannot detect contemporaneous relations among the variables. Third, timing relations may give a misleading idea of causation when expectations are important. For instance, suppose that an increase in the money stock is expected and that it will ultimately merely increase the price level. Prices in different sectors might rise at different times in anticipation of the higher money stock. One might then conclude that relative price variability causes the inflation, even though

21. C. W. J. Granger, "Investigating Causal Relations by Econometric Models and Cross Spectral Methods," Econometrica, vol. 37 (July 1969), pp. 424-38. 
Table 4. Granger Causality Tests, Selected Sample Periods, 1948:4 through 1980:3

\begin{tabular}{lcc}
\hline & \multicolumn{2}{c}{ Hypotheses and significance level } \\
\cline { 2 - 3 } $\begin{array}{c}\text { Dependent variable } \\
\text { and period }\end{array}$ & $\begin{array}{c}\text { Relative price } \\
\text { variability does not } \\
\text { cause inflation }\end{array}$ & $\begin{array}{c}\text { Inflation does not } \\
\text { cause relative } \\
\text { price variability }\end{array}$ \\
\hline VAR8 & & \\
$1948: 4-1980: 3$ & 0.05 & 0.02 \\
$1956: 1-1980: 3$ & 0.07 & 0.03 \\
$1956: 1-1972: 4$ & 0.32 & 0.45 \\
VARII & & \\
$1948: 4-1980: 3$ & 0.81 & 0.29 \\
$1956: 1-1980: 3$ & 0.01 & 0.06 \\
$1956: 1-1972: 4$ & 0.58 & 0.57 \\
\hline
\end{tabular}

Sources: Same as table 2.

a. The significance level is the probability of obtaining the sample observations if the hypotheses were, in fact, true-that is, if there were no causation. The procedure is to regress each variable on six lagged values of the other. If the right-hand variables are jointly significant, they Granger cause the left-hand variable. See the appendix for definition of the variables.

the increase in the money stock is really the cause of both the rise in the price level and the preceding changes in relative prices.

Despite these caveats, it would be of interest to know-if it were truethat increases in relative price variability precede changes in the inflation rate or vice versa. The formal Granger causality tests summarized in table 4 support the notion of mutual interactions between inflation and relative price variability. Table 4 presents results using $V A R 11$ and $V A R 8$ and their associated inflation rates. ${ }^{22}$ The tests show no significant Granger causal relations for 1956-72. However, for the $V A R 8$ measure, and at the 5 percent significance level, the hypothesis of no relation is often rejected: inflation causes relative price variability for 1948:4 through $1980: 3$ and 1956:1 through 1980:3, is caused by relative price variability in 1948:4 through $1980: 3$, and is almost significantly caused by relative price variability for 1956:1 through $1980: 3$. If $V A R 11$ is used, the causation runs relatively more strongly from variability to inflation. ${ }^{23}$

The Granger causality tests show no clear pattern of temporal precedence between the two variables. They thus make it doubtful that either

22. Causality tests using VAR16 gave essentially the same results as those using VAR11.

23. B. Dianne Pauls uses causality tests in the inflation and relative price variability context. See her "On the Causal Relationship between Inflation and the Dispersion of Relative Prices" (Massachusetts Institute of Technology, Department of Economics, December 1979). 
variable should be considered as the main actor in the relation between them. Rather, each probably causes the other or both are affected by the same disturbances to the economy. Given the likely mutual causation between inflation and relative price variability and the possible role of other shocks in inducing both, a useful way to characterize the links among policy, inflation, and relative price variability is to employ a vector autoregressive system in which all variables potentially cause each other.

\section{Vector Autoregressive Models}

A vector autoregressive system is a model in which a minimum of a priori theory is used to restrict the interrelations among the variables of interest. The procedure is to list the variables and treat them as potentially endogenous. Each variable in the system is then regressed on lagged values of itself and the remaining variables, perhaps along with a constant and a time trend. Because there is no explicit modeling of contemporaneous relations among the variables, the system is silent on possible simultaneous causal links among variables.

Vector autoregressive systems and their rationale have been described by Christopher Sims. ${ }^{24}$ In the context of this paper, in which there are many alternative mechanisms linking variables, vector autoregressions are best thought of as a convenient way of summarizing empirical regularities and perhaps suggesting the predominant channels through which relations work.

At the same time, the limitations of the approach should be recognized. Most important, it is assumed that there is a single stable model covering the entire period. Furthermore, policy is necessarily assumed to have behaved according to a consistent set of rules over the sample period. Because there is no explicit underlying structural interpretation of the system, it is not possible to answer the question of whether alternative policy rules would alter the behavior of the economy. ${ }^{25}$ The question that the

24. Christopher A. Sims, "Macroeconomics and Reality," Econometrica, vol. 48 (January 1980), pp. 1-48.

25. This point is emphasized by John Taylor in his comments on this paper. $\mathrm{He}$ also suggests that international comparisons could help in examining the effects of alternative policy responses. Below I present a brief comparison of U.S. with German and Japanese experience. 
vector autoregression system asks about policy is whether policy disturbances-that is, unanticipated policy changes-affect the behavior of other variables. But to reiterate, the approach does not provide information on whether a different type of policy response to other disturbances would have produced more desirable macroeconomic behavior. Other limitations of the approach are discussed below as appropriate.

The vector autoregressive models estimated here for the United States all include at least the six variables specified below. There are two basic systems: the six-variable system; and an eight-variable system that treats energy and food prices separately.

\section{Six-variable}

FH Full employment surplus divided by GNP

$R M 2 Q \quad$ Quarterly growth rate of M2

PI11 Quarterly inflation rate, eleven-component personal consumption expenditure (PCE) deflator

VAR11 Variability of relative prices, eleven-component PCE deflator

$R G N P$ Quarterly growth rate of real GNP

$R T B \quad$ Three-month Treasury bill rate

Eight-variable ( $F H, R M 2 Q, R G N P, R T B)$, plus the following

PIEN Quarterly inflation rate, energy components of PCE deflator

$P I F O \quad$ Quarterly inflation rate, food component of PCE deflator

PI8 Quarterly inflation rate, eight-component PCE deflator

$V A R 8$ Variability of relative prices, eight-component PCE deflator

In the former the inflation variables are those corresponding to the elevencomponent personal consumption expenditure deflator; in the latter the inflation variables correspond to the eight-component deflator. Lag lengths for all variables are set at three quarters to conserve degrees of freedom. ${ }^{26}$ Because the variables on the right-hand side of each equation are the same and there are no constraints on the coefficients, the ordinary least squares technique is an efficient estimator. ${ }^{27}$

The estimated equations are difficult to interpret and are not presented. The properties of the system are best understood by examining the contemporaneous correlations among disturbances in the different equations, shown in table 5, and the so-called impulse response functions (IRFs), shown below. The IRFs can be viewed as dynamic multipliers that give the current and subsequent effects on each variable of a shock to one of those

26. Adding a fourth lag does not substantially modify any conclusions.

27. Computations were made using the RATS program. 
Table 5. Correlation Matrix of Contemporaneous Disturbances, Six- and Eight-Variable Vector Autoregressive Models, 1956:1 through 1980:3 ${ }^{\mathrm{a}}$

\begin{tabular}{|c|c|c|c|c|c|c|c|}
\hline Variable & PIEN & $P I F O$ & $F H$ & $R M 2 Q$ & $\begin{array}{c}(P I 11) \\
P I 8\end{array}$ & $\begin{array}{c}(V A R 11) \\
\text { VAR8 }\end{array}$ & $R G N P$ \\
\hline PIFO & -0.148 & & & & & & \\
\hline$F H$ & -0.005 & 0.246 & & & & & \\
\hline$R M 2 Q$ & 0.073 & -0.116 & $\begin{array}{c}(-0.193) \\
-0.163\end{array}$ & & & & \\
\hline $\begin{array}{l}(P I 11) \\
P I 8\end{array}$ & 0.072 & 0.186 & $\begin{array}{c}(0.220) \\
0.228\end{array}$ & $\begin{array}{c}(-0.130) \\
-0.154\end{array}$ & & & \\
\hline$(V A R 11)$ & & & $(0.127)$ & $(0.053)$ & $(0.387)$ & & \\
\hline$V A R 8$ & 0.040 & -0.130 & $\begin{array}{c}-0.047 \\
(-0.022)\end{array}$ & $\begin{array}{c}0.060 \\
(-0.039)\end{array}$ & $\begin{array}{r}0.225 \\
(-0.100)\end{array}$ & $(0.091)$ & \\
\hline$R G N P$ & -0.025 & -0.243 & $\begin{array}{c}-0.023 \\
(0.084)\end{array}$ & $\begin{array}{c}-0.070 \\
(-0.376)\end{array}$ & $\begin{array}{r}-0.032 \\
(0.358)\end{array}$ & $\begin{array}{c}0.052 \\
(0.493)\end{array}$ & $(0.295)$ \\
\hline$R T B$ & 0.309 & 0.094 & 0.023 & -0.516 & 0.154 & -0.062 & 0.299 \\
\hline
\end{tabular}

Source: Citibank Economic Database.

a. See text for definition of the six- and eight-variable systems. Entries in parentheses are correlations between contemporaneous disturbances in a six-variable system; all other entries, an eight-variable system. The variables are as follows: $P I E N$-inflation rate of energy; $P I F O$-inflation rate of food; $F H$-full employment surplus divided by GNP; $R M 2 Q$-quarter-to-quarter M2 growth rate; (PIII) $P I 8$-quarter-toquarter inflation rate; $(V A R 11) V A R 8$-variability of relative prices; $R G N P$-quarter-to-quarter growth rate of real GNP; and $R T B$-Treasury bill rate.

variables. The IRFs represent each variable in the system as a moving average of current and past disturbances.

\section{RELATIONS IN THE SIX-VARIABLE SYSTEM}

The contemporaneous correlations for the six-variable system, in which prices of food and energy are not treated separately from other prices, are shown in parentheses in table 5. The correlations involving the variability of relative prices, $V A R 11$, are of most interest. VAR11 has a relatively high contemporaneous correlation with the disturbances in the equations for the inflation rate and the Treasury bill rate. The correlation with the rate of inflation disturbances is understandable in the light of the first section of this paper, but the reasons for the strong link with the Treasury bill rate are unclear. ${ }^{28}$

28. A major difficulty in using the vector autoregressive approach is that there are reasons to think relative price variability is a nonlinear function of the shocks to the system-for instance that VAR11 depends on the absolute values of disturbances. I take account of this problem in the section on nonlinear variability problems below. 
These correlations have little to say about causation. For instance, it might seem from the relation between $V A R 11$ and $R M 2 Q$ (M2 growth rate) that an innovation - that is, unpredicted movements-in money increases relative price variability. But table 5 is also consistent with the argument that an increase in $V A R 11$ is typically a supply shock and that output would have declined if the money stock had not grown to offset the shock. Perhaps the most striking feature of the table is the high correlation between the Treasury bill rate innovations and the variables in the last four columns. ${ }^{29}$ The negative contemporaneous correlation between money growth and the Treasury bill rate innovations is a robust feature of the systems with which I have worked.

Table 6 shows IRFs for the six-variable system. The IRFs show the current and subsequent effects on all variables of a disturbance or innovation in a given variable. For instance, the IRFs associated with a money disturbance indicate the effects on subsequent money growth and contemporaneous and subsequent values of other variables of an unpredicted increase in the money stock.

Because the disturbances are correlated, as seen in table 5, a decision has to be made on how to assign credit for the correlations. Should one say, for instance, that when the growth rate of money is high it is also implied that the Treasury bill rate is low, which is what the correlations of table 5 imply? Or should one ignore the contemporaneous correlations between money and Treasury bill rates and other variables? For instance, the Treasury bill rate could be assumed to be somehow held constant when the growth rate of money is unexpectedly high. This is essentially what is done in interpreting coefficients in standard regressions. Even though the right-hand variables in a regression are correlated, one does not usually assume when interpreting coefficients that any variable changes occurred except the one of interest.

The alternative approach, suggested by Sims and adopted here, is to assign credit for any correlations among the variables. The variables are ordered in a way that either reflects a judgment about causation or exogeneity, or else does not prejudge the hypothesis being examined. The

29. The role of interest rate innovations has been emphasized by Sims. See Christopher A. Sims, "Comparison of Interwar and Postwar Business Cycles: Monetarism Reconsidered," American Economic Review, vol. 70 (May 1980, Papers and Proceedings, 1979), pp. 250-57. See also Robert B. Litterman and Laurence Weiss, "Money, Real Interest Rates, and Output," Working Paper 179 (Federal Reserve Bank of Minneapolis, September 1981). 
Table 6. Impulse Response Functions, Six-Variable System, 1956:1 through 1980:3

\begin{tabular}{|c|c|c|c|c|c|c|c|}
\hline $\begin{array}{c}\text { Impulse } \\
\text { variable, } \\
\text { in order } \\
\text { applied }\end{array}$ & Period $^{\mathrm{b}}$ & $F H$ & $R M 2 Q$ & $P I 11$ & $V A R I 1$ & $R G N P$ & $R T B$ \\
\hline$F H$ & $\begin{array}{c}1 \\
2 \\
S(3,4) \\
S(5,8)\end{array}$ & $\begin{array}{l}\mathbf{0 . 5 0} \\
0.33^{\mathrm{e}} \\
0.57 \\
0.61\end{array}$ & $\begin{array}{l}-0.40^{\mathrm{d}} \\
-0.36^{\mathrm{e}} \\
-0.80 \\
-0.21\end{array}$ & $\begin{array}{r}0.25^{\mathrm{d}} \\
0.05 \\
0.17 \\
-0.16\end{array}$ & $\begin{array}{l}0.14 \mathrm{e} \\
0.02 \\
0.22 \\
0.25\end{array}$ & $\begin{array}{l}-0.07 \\
-0.71^{\mathrm{e}} \\
-0.26 \\
-0.48\end{array}$ & $\begin{array}{r}0.07 \\
0.04 \\
0.20 \\
-0.06\end{array}$ \\
\hline$R M 2 Q$ & $\begin{array}{c}1 \\
2 \\
S(3,4) \\
S(5,8)\end{array}$ & $\begin{array}{r}0.00 \\
0.00 \\
-0.13 \\
-0.22\end{array}$ & $\begin{array}{c}2.01 \\
1.03^{\mathrm{d}} \\
-0.21 \\
0.06\end{array}$ & $\begin{array}{r}-0.10^{e} \\
0.04 \\
0.04 \\
-0.06\end{array}$ & $\begin{array}{l}0.09 \mathrm{e} \\
0.18^{\mathrm{d}} \\
0.02 \\
0.09\end{array}$ & $\begin{array}{c}-0.13 \\
0.41^{\mathrm{d}} \\
0.96 \\
0.12\end{array}$ & $\begin{array}{c}-0.29 \mathrm{c} \\
-0.15^{\mathrm{d}} \\
0.03 \\
-0.25\end{array}$ \\
\hline PIII & $\begin{array}{c}1 \\
2 \\
S(3,4) \\
S(5,8)\end{array}$ & $\begin{array}{l}0.00 \\
0.07 \\
0.13 \\
0.01\end{array}$ & $\begin{array}{c}0.00 \\
-0.42^{\mathrm{e}} \\
-0.87 \\
-0.70\end{array}$ & $\begin{array}{l}1.09 \\
0.54 \mathrm{e} \\
0.99 \\
0.78\end{array}$ & $\begin{array}{l}0.41^{\mathrm{c}} \\
0.21^{\mathrm{d}} \\
0.43 \\
0.18\end{array}$ & $\begin{array}{l}-0.30^{\mathrm{e}} \\
-0.35^{\mathrm{e}} \\
-1.48 \\
-2.13\end{array}$ & $\begin{array}{l}0.25^{\mathrm{c}} \\
0.21^{\mathrm{d}} \\
0.52 \\
0.22\end{array}$ \\
\hline$V A R 11$ & $\begin{array}{c}1 \\
2 \\
S(3,4) \\
S(5,8)\end{array}$ & $\begin{array}{l}0.00 \\
0.03 \\
0.13 \\
0.13\end{array}$ & $\begin{array}{r}0.00 \\
0.10 \\
-0.79 \\
-0.23\end{array}$ & $\begin{array}{l}0.00 \\
0.20 \\
0.65 \\
0.53\end{array}$ & $\begin{array}{l}1.00 \\
0.15^{\mathrm{d}} \\
0.32 \\
0.21\end{array}$ & $\begin{array}{r}0.44^{\mathrm{d}} \\
-0.11 \\
-0.56 \\
-1.73\end{array}$ & $\begin{array}{l}0.34^{\mathrm{c}} \\
0.00 \\
0.71 \\
0.27\end{array}$ \\
\hline
\end{tabular}

Memoranda

Standard devia-

tions of dis-

turbances

$\begin{array}{llllllll}\sigma_{1} & \cdots & 0.50 & 2.05 & 1.12 & 1.09 & 2.96 & 0.71 \\ \sigma_{2} & \cdots & 0.50 & 2.01 & 1.09 & 1.00 & 2.91 & 0.57\end{array}$

Source: Same as table 5.

a. Entries represent responses of each variable in the periods indicated to a shock of one standard deviation in period 1 in the impulse variable. The size of the standard deviation is listed in the last row. Entries for $V A R 11$ have been normalized so that the standard deviation of the VARII disturbances equals 1.00 . The variables are described in table 5, note a. Impulse responses depend on ordering of the variables. The $\sigma_{1}$ is the standard deviation of the error term in regressions for each variable; the $\sigma_{2}$ is the standard deviation of orthogonalized disturbances and depends on the ordering of the variables. The entries that correspond to the impulses are in boldface.

b. The period indicates the time after the initial shock in which the response occurs. The impulse occurs in period 1 . The $S(3,4)$ is the sum of responses to impulses in periods 3 and 4 ; the $S(5,8)$ is the sum of responses to impulses in periods 5 through 8 .

c. The estimated effect is more than double its simulated standard error.

d. The estinated effect is larger than its simulated standard error.

e. The estimated effect is larger than 0.5 times its simulated standard error.

variables that are higher in the ordering receive the credit for any correlations between those variables and the ones lower in the order. For instance, in table 6 the full employment surplus as a percentage of GNP is first in the order. When it changes, it is also assumed that other variables lower in the order change-and the effects of those changes in the variables lower in the order are attributed to the full employment surplus. The 
extent of the change in each variable reflects its correlation with the variables higher in the ordering in table 6 . The second variable in that ordering is money growth. The IRFs associated with money growth innovations have all had the effects due to correlations between money growth and the full employment surplus removed. But to the extent that there remains correlation between money growth disturbances and disturbances in variables lower in the order (after correlations with the full employment surplus have been removed), the associated changes in the variables lower in the ordering are attributed to money growth. So it proceeds throughout the ordering.

The ordering of the variables is of no consequence if the disturbances are orthogonal or not correlated initially. But the ordering might matter in other cases. If the variables are highly correlated, it becomes difficult to disentangle the effects of innovations in one variable on others. To the extent that there is uncertainty about the appropriate ordering of the variables, it is desirable to investigate whether any conclusions are affected by the ordering chosen.

The IRFs are presented for two reasons. The first is to determine how, in the sample period examined, other variables affect the variability of relative prices. The second is to ascertain how innovations in the variability of relative prices affect other macroeconomic variables.

To do this, the variables are ordered as in table 6 . The two policy variables go first to give policy an opportunity to play a large role in generating relative price variability. The inflation rate goes next to allow it, too, to have a large role in affecting $V A R 11$. The last two rows of table 6 provide some indication of the effects of the ordering in reducing the standard deviations of the innovations in individual equations. ${ }^{30}$ The role of the ordering is evidently important for the Treasury bill rate.

Tests of statistical significance for the coefficients in the IRFs are not made in a routine way. Because the IRFs are nonlinear and convoluted functions of the estimated coefficients in the model, it is easier to generate estimates of the confidence bounds using stochastic simulations than to do

30. The $\sigma_{1}$ row shows the standard deviation of the error term in each regression in the vector autoregressive system before the disturbances are orthogonalized. The $\sigma_{2}$ row indicates the standard deviation of each error term after the effects of correlations with variables higher in the ordering have been removed. This gives some indication of the effects of the ordering but is not completely informative when some of the disturbances are negatively correlated, as they are here. 
so analytically from the covariance matrix of the estimated coefficients. In these stochastic simulations both the matrix of coefficients in the vector autoregressive system and the covariance matrix of contemporaneous residuals are treated as stochastic. Ratios of coefficients to their standard errors exceeding 2.0,1.0, and 0.5 are identified in the table. ${ }^{31}$

In table $6, \mathrm{I}$ show the effects of innovations in other variables on the variability of relative prices in the VAR11 column. Innovations in both the full employment surplus and the growth rate of money increase the variability of relative prices, as does an increase in the inflation rate. An innovation in the inflation rate should be understood as an increase in that rate that is not explained either by lagged events or by innovations in variables higher in the order-in this case, fiscal and monetary policy. Because there is a high contemporaneous correlation between innovations in inflation and relative price variability in table 5 , the vector autoregressive approach is unable to determine which of those two variables causes the other.

Proceeding now across the $V A R 11$ row in table 6, one finds that relative price variability has no significant effects on variables higher in the ordering. Surprisingly, an innovation in relative price variability accompanies an increase in GNP growth. A VAR11 innovation also accompanies an increase in the Treasury bill rate. The effects of VAR11 on money growth are not statistically significant but appear to show some slight accommodation of relative shocks, followed by subsequent restriction of money growth as the inflationary consequences work through the economy.

Although the evidence contained in table 6 is interesting in showing that other macroeconomic variables affect the variability of relative prices and that variability in turn appears to have independent macroeconomic effects, the high contemporaneous correlation between inflation and relative price variability in the table ensures that the vector autoregressive approach will not by itself be able to sort out the causality issue between the two variables. To the extent that the correlation is contemporaneous, either variable may be responsible for the variability in the other-or each may be caused by other disturbances.

31. Christopher Sims argues that since no $t$-statistics or tests of significance were used in guiding the search for an appropriate model to use, $t$-statistics lower than the conventional levels for significance are of interest. 
THE SPECIAL ROLE OF FOOD AND ENERGY PRICES

Given the many indications that the relation between variability and inflation is dominated in the sample period by energy and food shocks, it is sensible to remove these variables and treat them separately from the general rate of inflation. The eight-variable system does that, and for that purpose uses for the inflation and variability measures $P I 8$ and $V A R 8$, so that it is possible to deal with the variability of relative prices other than food and energy.

The contemporaneous correlations among disturbances from the vector autoregressions for the eight-variable system, which treats food and energy prices separately, are shown in table 5 by the entries not in parentheses. The difference in the correlations between certain variables in the six- and eight-variable systems is of particular interest. The contemporaneous correlation between the Treasury bill rate and the variability of relative prices, the highest correlation in the six-variable system discussed previously, now disappears. The correlation between the inflation rate and the Treasury bill rate is substantially reduced, and that between money growth and the bill rate increased in absolute value. The correlation between the inflation rate and relative price variability is reduced from 0.387 to 0.225 . Thus the addition of the two extra variables substantially affects contemporaneous relations. Further, it simplifies the interpretation of causation by reducing the contemporaneous correlation between inflation and relative price variability.

The IRFs for the new system are shown in table 7. Again, I begin by discussing entries in the $V A R 8$ column. The highly significant association between inflation and relative price variability disturbances has now disappeared. Money growth is the variable that is now most closely associated with relative price variability. There is also some small contribution from the full employment surplus. Otherwise, the variability of relative prices seems largely to follow its own path.

Proceeding down the $V A R 8$ row, there is little significance attached to the macroeconomic effects of increases in the variability of relative prices, as was the case in the six-variable system. In table 7 the variability of relative prices seems no longer either to be an important macroeconomic factor or to be importantly associated with inflation. The clear impression is that the strong relation between relative price variability and inflation ob- 


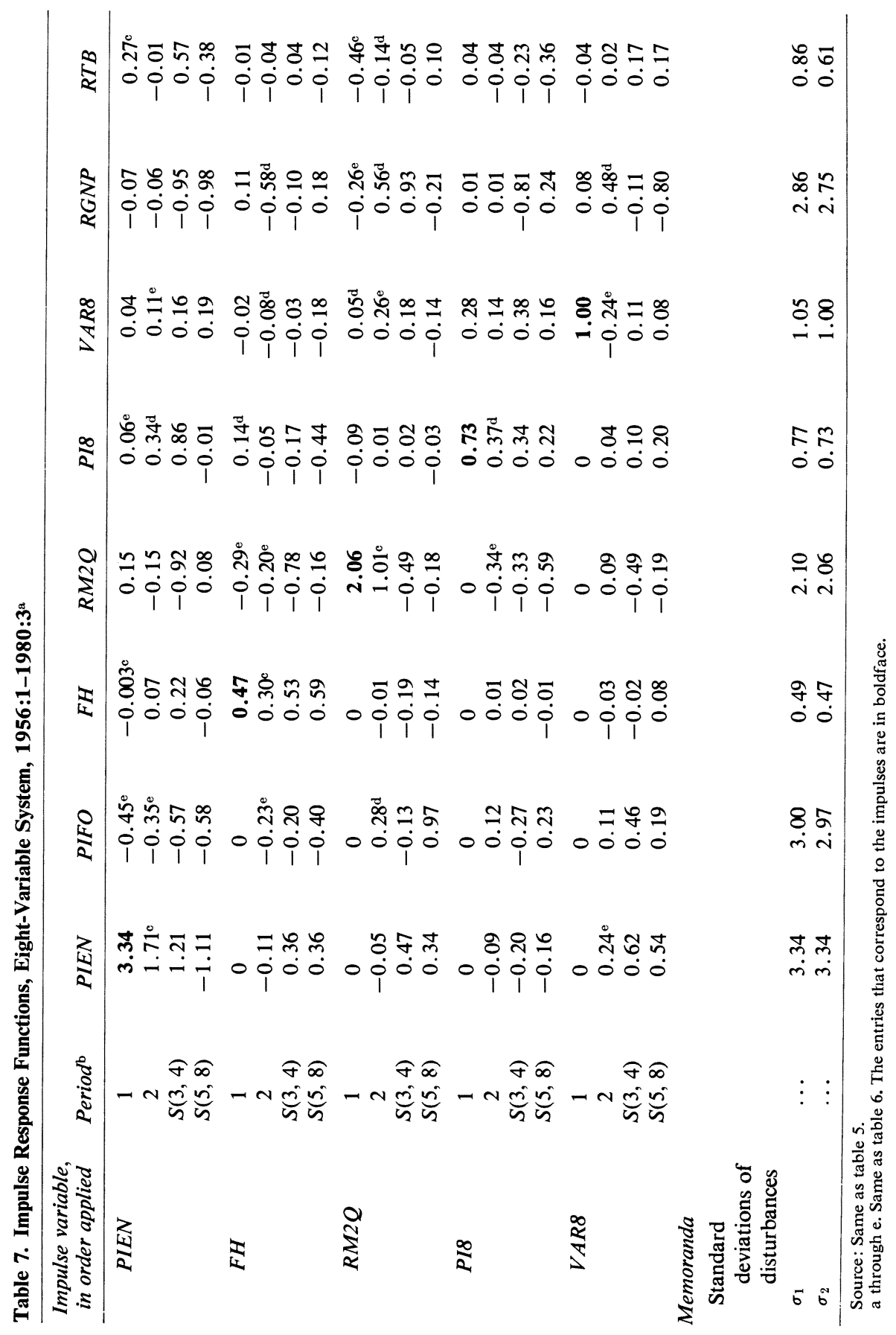


served in the six-variable system and in the regressions above is a result of the effects of food and energy shocks.

\section{VARIANCE DECOMPOSITIONS}

It is possible to define more precisely what part of the variation in each of the variables in the vector autoregressive system is accounted for by itself and the remaining variables. This is done by calculating variance decompositions, which show the proportions of the variance of each variable that is accounted for by innovations in that same variable and other variables.

Looking ahead over any horizon, one notes that all the variables are likely to diverge from their currently expected levels. It is quite certain that shocks, innovations, or unexpected events will occur that will move variables (such as the inflation rate) away from the levels to which they would otherwise tend to be moving.

The estimated coefficients and variance-covariance matrix of the vector autoregressive model imply both the typical amounts by which variables (again, like the inflation rate) may diverge in either direction from the levels to which they otherwise tend to move, and the likely causes of such divergences. For instance, it might be that over the sample period the main reason the inflation rate moves away from its expected value is that there are unpredicted changes in the money stock. The variance decompositions show what proportion of movements of variables away from the levels to which those variables otherwise tend is accounted for by own innovations and by innovations in other variables.

The variance decomposition typically differs, depending on how far ahead one looks. Innovations in any variable (the money supply, for example) take time to work through the system. Thus changes in the money stock could, over longer periods, account for more of the deviations of other variables from their trend levels than they would if one looked just one period ahead. Table 8 shows variance decompositions for two and eight periods ahead. The typical pattern is that short-run deviations of variables from the levels to which they were tending are the result mainly of own innovations; over longer periods the dynamics of the system have time to work themselves out, and interactions are expressed in the form of a large role for innovations in other equations in affecting 


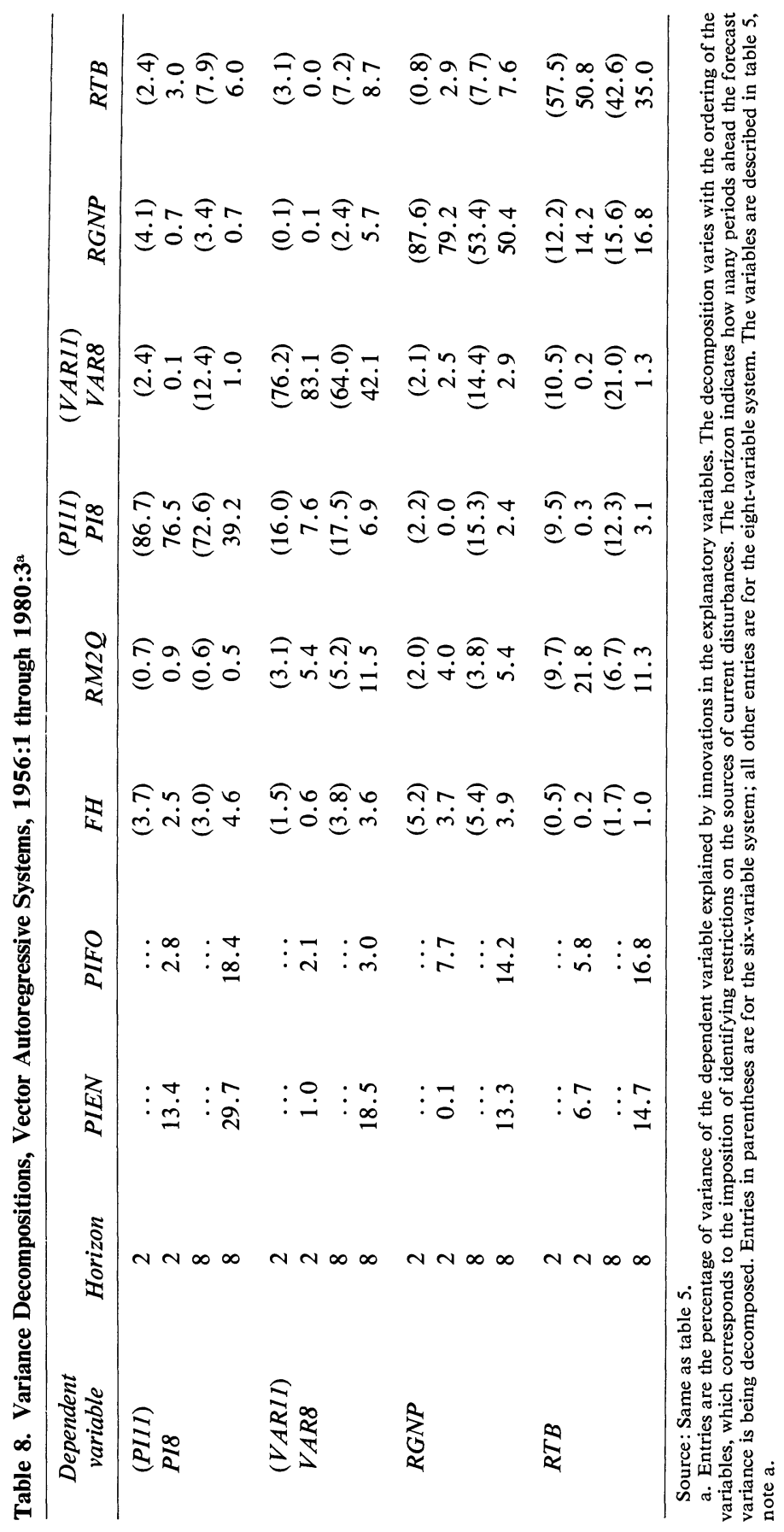


the behavior of any given variable. Period 2 rather than period 1 is chosen because the effect of ordering, which does affect the variance decomposition, is so evident in period 1 . By period 8 , the variance decompositions have essentially all converged to their asymptotic values, reflecting rapid dynamics in the system. As before, the entries in parentheses in table 8 refer to the six-variable system; those without parentheses, to the eight-variable system that treats food and energy prices separately.

Six-Variable System. The main interest in this table is in the rows and columns associated with relative price variability. In the six-variable system the relation between the inflation rate and variability dominates for the two-period horizon. Fiscal, monetary, and interest rate innovations play small roles.

By period 8 the relative importance of other variables has increased. Fiscal and monetary policy each explain a small part of the variance of relative prices, though most of the forecast error still results from own innovations. The role of the interest rate innovations remains a mystery. ${ }^{32}$ They may be related to money-demand disturbances, which in a system like this are bound to reduce the significance of innovations in the money stock. Changes in monetary policy may be more accurately reflected in changes in the Treasury bill rate than in the money stock itself. Alternatively, the Treasury bill rate may be important because it reflects expectations of future disturbances. To the extent that expectations are formed in a way that is not captured by the time series behavior of the variables in the vector autoregressive system, they may be expressed within this system in the Treasury bill rate, which is known to be forward looking.

Scanning the $V A R 11$ column in table 8 for the six-variable system, one finds that the variability of relative prices apparently plays an important macroeconomic role. After eight periods it accounts for 12 percent of the variance of the inflation rate, 14 percent of the variance of GNP growth, and 21 percent of the variance of the Treasury bill rate. ${ }^{33}$ In each case this is a larger part of the variance than is explained by any innovation other than own innovation. Moreover, the ordering of the variables is such that monetary, fiscal, and inflation innovations receive credit for any of their contemporaneous correlations with relative price variability innovations.

32. The importance of these innovations is pointed out by Christopher Sims in "Monetarism Reconsidered."

33. After eight periods $V A R 11$ accounts for 3 percent of the variance of $F H$ and 5.5 percent of the variance of $R M 2 Q$. 
The decompositions for the six-variable system in table 8 suggest that relative price variability is largely autonomous, is to a considerable extent affected by autonomous movements in the inflation rate, and is only slightly influenced by other macroeconomic variables. Monetary and fiscal innovations account for only a small part of the observed variation in relative price variability. This variability in turn accounts for a substantial part of the variance of inflation and of GNP. Because the contemporaneous correlation between the inflation rate and the variability measure is high (0.387), the contributions of each to explaining the variance of the other depend on the ordering of the variables.

A major point is made in the six-variable system in table 8: monetary and fiscal variability account for little of the observed variation of macroeconomic variables in the post-1956 U.S. economy. It appears from the table that relative price variability is itself a major source of macroeconomic variability.

Eight-Variable System. Figure 2 and the IRFs both suggest that food and energy price shocks dominate the behavior of the VARI1 index of relative price variability. This implies that the apparent macroeconomic significance of relative price variability may, for this sample period, merely be a proxy for the importance of food and energy price shocks during the period. To examine this possibility, food and energy inflation are separated from the variability measure, and $V A R 8$ is used instead of $V A R 11$ in a vector autoregressive model. An examination of the VAR8 column in table 8 shows that, after two periods, own variance is even more dominant than before. The role of inflation is reduced and that of money increased. A small share of variance is accounted for by the energy and food price innovations.

By period 8 the results for the eight-variable system are very different from that of the six-variable system. The most important single variable accounting for the variance of $V A R 8$ other than itself is the price of energy. The role of monetary innovations has been increased and that of inflation innovations substantially reduced. One can now attribute more than 10 percent of the variance (after eight periods) of $V A R 8$ to monetary innovations and about 5 percent each to fiscal, inflation, and GNP innovations. The role of the Treasury bill rate is not much changed.

The importance of the variability of relative prices as a macroeconomic variable disappears in the $V A R 8$ column. For the four variables where rows are missing from the table the maximum share of variance ac- 
counted for by $V A R 8$ after eight periods is 1.4 percent. For the three other variables the maximum percentage of variance accounted for by $V A R 8$ is 2.9 percent for GNP.

Table 8 provides convincing evidence that energy and food price shocks dominate the relations among macroeconomic variables-particularly the inflation rate-and relative price variability for this sample period. At the same time, the results do not rule out some role for unanticipated monetary disturbances as a cause of relative price variability, since money innovations are the most important nonenergy variable affecting relative price variability. Indeed, once the energy and food price disturbances are removed from the variability measure, monetary disturbances are seen to play a larger role in causing relative price variability. For this period, fiscal innovations, as measured by the full employment surplus, play a smaller role than money. ${ }^{34}$

Two questions remain in this section. First, would the chief resultsthat relative price variability has no major macroeconomic role and that policy surprises were not directly responsible for relative price variability over the same period-be affected by a reordering of the variables? Variance decompositions under two reorderings of the variables are presented in table 9 , together with the decompositions using the ordering of table 8 . In the "table 8 ordering" of table 9, the Treasury bill rate is first in the order and energy and food price shocks last. In the first alternative ordering, the inflation rate comes first, and money precedes the Treasury bill rate. Food and energy prices are once more last in the ordering. The absence of major macroeconomic effects of relative price variability is totally confirmed by these reorderings. ${ }^{35}$ In no case does $V A R 8$ account for more than 4 percent of the variance of any of the other variables. It does appear, though, that food-price inflation becomes much less important when it is last in the ordering. The energy price shocks retain their important role.

Conclusions about the role of policy surprises in causing relative price

34. I have estimated the eight-variable system with an inflation-adjusted full employment surplus, calculated by adding back capital gains on the debt. This does not increase the share of the variance of $V A R 8$ accounted for by the fiscal variable. It does, however, increase the share of inflation explained by fiscal policy, since the full employment surplus is then highly correlated with the inflation rate. Due to the ordering of the variables in the system, an increase in the full employment surplus is recorded as increasing the inflation rate.

35. These results are not shown explicitly. 


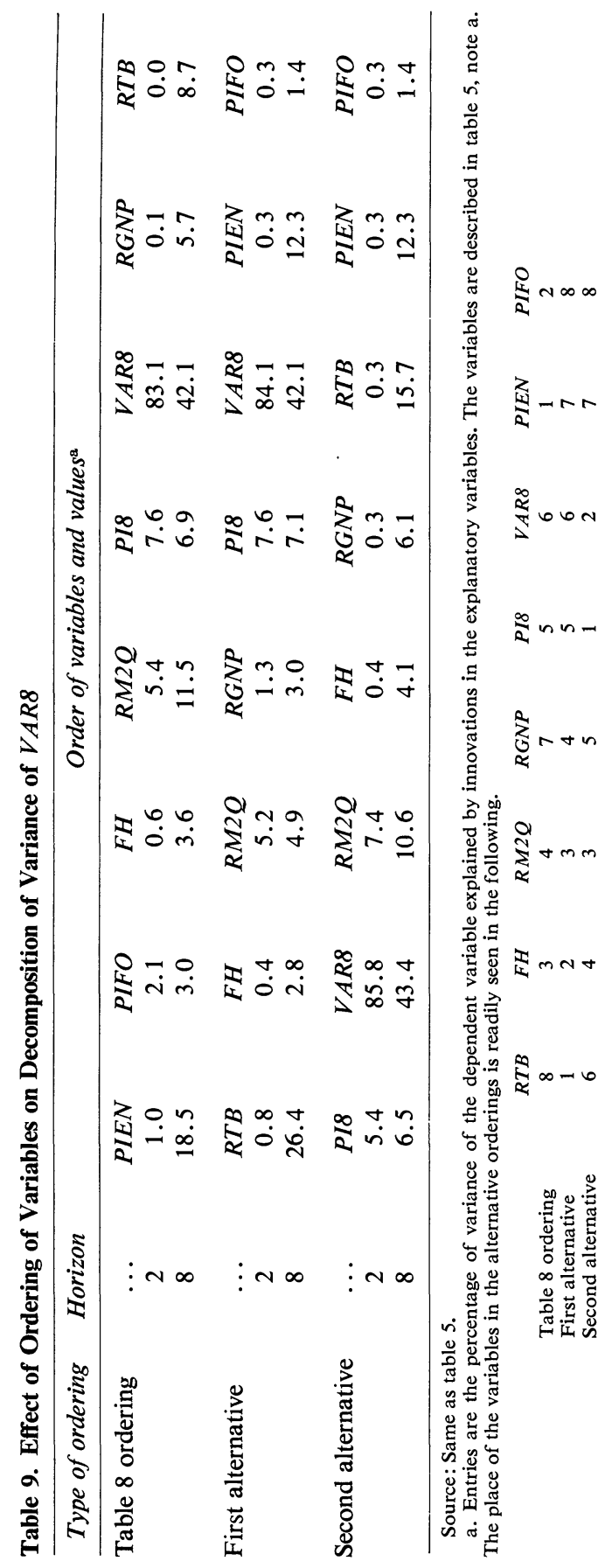


variability depend heavily on the interpretation of the role of interest rate innovations. If these innovations are seen as the results of monetary policy, the results of table 9 suggest a major role for monetary policy in affecting relative price variability. Under each of the orderings in table 9 at least 20 percent of the variance of relative price variability after eight periods is accounted for by money and interest rate innovations jointly, with the Treasury bill rate the more important in two of the three orderings shown. Thus there is some evidence that monetary policy disturbances account for a sizable part of relative price variability during this period. However, as noted earlier, it is still not clear what significance should be attached to the important role of interest rate innovations in vector autoregressive systems and in the trade cycle.

The second question is one of statistical significance. In the absence of confidence intervals, it is not certain that the results presented in tables 8 and 9 are statistically significant. To the extent that the issue is whether the variability of relative prices has major macroeconomic effects, the absence of statistical significance tests is not important because in any event the absolute magnitude of the share of relative price variability in explaining other variables is small. For deciding whether policy variables are significantly responsible for relative price variability, it is clear that the answer will depend both on the ordering of the variables and on the interpretation of the role of the interest rate as a policy variable. Since stochastic simulations of IRFs showed large standard errors for horizons exceeding three quarters, it is quite likely that most or all the variance decompositions at the eight-period horizon shown in tables 8 and 9 are not significantly different from zero.

\section{NONLINEAR RESPONSES}

I now return to the issue of the linearity of the response of relative price variability to disturbances. As noted above, many of the approaches linking relative price variability and inflation suggest that responses depend on the absolute values of the disturbances. The absence of deflation during the sample period does not allow one to test whether price increases and decreases have different effects. But as regression 3-9 in table 3 indicates, and the first, fourth, and fifth approaches summarized in table 1 predict, there is a nonlinear response of relative price variability to disturbances. 
I have estimated a seven-variable system that excludes $V A R 8$ since it is not a major determinant of the other variables in the eight-variable system..$^{36}$ Residuals from the resulting system are then used as regressors in equations for $V A R 8$. Both algebraic and absolute values of residuals are included for all variables entering a regression. Contemporaneous and seven lagged values for each of the disturbances are entered; lag distributions are estimated imposing second-order Almon lag constraints with right endpoint constrained to zero. The constraints were imposed to conserve degrees of freedom.

Stepwise regressions are calculated, with the variables entered in the order in which they appear in table 7. The full employment surplus is omitted because it is clear that it has almost no explanatory power for the variability of relative prices. The marginal contribution of each set of disturbances to explaining $V A R 8$ is shown below. ${ }^{37}$

$\begin{array}{lcccccc} & \text { PIEN } & \text { PIFO } & \text { RM2Q } & \text { PI8 } & R G N P & R T B \\ V A R 8 & & & & & & \\ 1958: 1-1980: 3 & 12.0 & 14.0 & 8.1 & 2.5 & 1.0 & 2.1\end{array}$

Food and energy prices once more play a large role and so do moneysupply disturbances. Since the regressors are not orthogonal, the implicit decomposition displayed here depends on the order in which the variables enter the regressions. If other variables shown in the table are omitted from the regressions, money shocks by themselves account for 15 percent and money and inflation shocks together account for more than 20 percent of the variance of $V A R 8$.

The evidence of this section is that money shocks are assigned a larger share of the blame for relative price variability than is suggested above once the nonlinearity of the response of variability to disturbances is taken into account. At the same time, food and energy price disturbances continue to play a major role in explaining relative price variability of prices of other goods.

36. This obviously could result from inappropriate linearity assumptions.

37. Entries represent the marginal contribution, in percent, of each set of regressors (algebraic and absolute values of residuals from seven-variable vector autoregressions) in explaining the variance of $V A R 8$. Percentages are calculated on the basis of the sum of the squared residuals of the regression of $V A R 8$ on a constant and trend term. 


\section{Welfare Significance of Relative Price Variability}

The recent focus on inflation and relative price variability arises from the suspicion that inflation has something to do with poor economic performance. The notion is that inflation is associated with relative price variability that is unrelated to relative scarcities and hence leads to misallocations of resources. The point is a central feature of the imperfect information market-clearing approach in which relative prices change inappropriately as a result of monetary disturbances.

The simple welfare economics is illustrated in figure 4 . With full information, the economy would be at point $A$. In the imperfect information situation, the economy could move to point $B$ remaining on the production possibility frontier if the distortion affected only the relative prices of final goods. Markets clear as if there are distortions, like tariff wedges between actual and correct prices. So long as the economy remains on the production possibility frontier, the degree of change in relative prices from their ratio at $A$ will indicate the extent of the distortion.

But with misperceptions there is no reason for economy to remain on the production possibility frontier. Production might well become inefficient relative to the perfect information optimum; for instance, labor might be imperfectly informed about relative wages and not be allocated efficiently. In such a case, the economy moves to point $C$. Relative prices of final goods at $C$ may or may not differ from those at $A$. Even if they do not, there is still a welfare loss from the inefficiency reflected in the smaller scale of production. In general, the relative prices of final goods are no longer a measure of welfare loss relative to the optimum. It is necessary to look at factor prices also or to use a measure of distance from the production possibility frontier along with relative prices to pin down the welfare loss at $C$ relative to $A$. If one explains unemployment or other indications of being off the production possibility frontier as reflecting a lack of market clearing, then a fortiori prices do not provide a measure of the welfare loss.

This discussion raises a general question. Relative price variability associated with inflation is of interest because of the suspicion that inflationary shocks associated with policy have undesirable welfare effects. 
Figure 4. Misallocations Caused by Imperfect Information

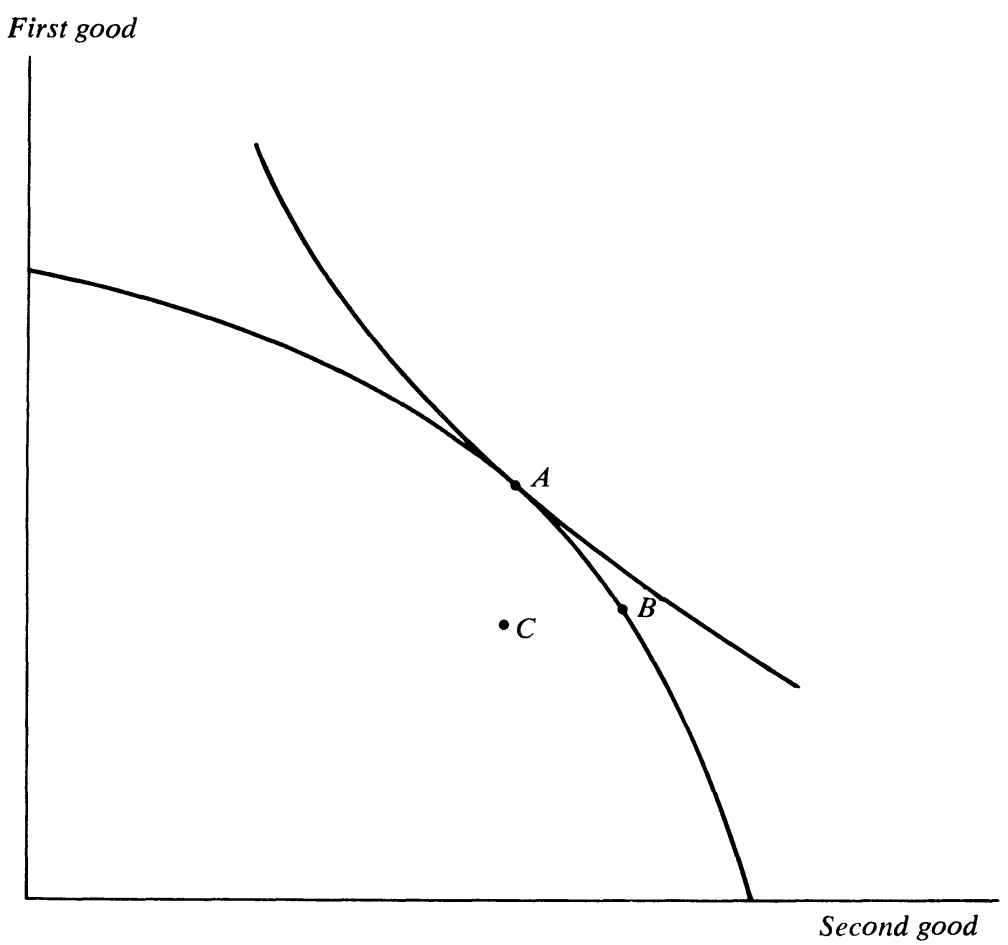

The general question is, why look at relative price variability rather than a more direct measure of welfare to detect any effects of policy or other shocks? If the welfare or utility function of consumers were known, and if one could trace the effects of the shocks on the quantities that enter the welfare function, one would then be able to examine the effects of shocks on welfare directly. If monetary shocks were the predominant source of welfare loss, inappropriate monetary policy would be blamed for the poor performance of the economy. There would be no need to examine relative price variability, which serves at best as a very indirect measure of welfare.

Lacking any better measure of social welfare, we make use of an output measure, real GNP, as an approximation. To illustrate the relation between theoretical welfare measures and output, suppose $U(X)$ is a utility function and $X$ is a vector of outputs and inputs. Some, like labor, may 
have negative marginal utility. ${ }^{38}$ Around any point $\bar{X}$, one can expand the utility function in Taylor series to obtain

$$
\Delta U(X)=\Sigma_{i} U_{i} \Delta X_{i}+\sum_{i} \sum_{j} \Delta X_{i} U_{i j} \Delta X_{j}+\ldots .
$$

Equation 2 can be made exact by evaluating the partial derivatives, $U_{i}$, and the Slutsky matrix, $U_{i j}$, at an appropriate point. Ignoring labor input, the first sum in 2 corresponds approximately to GNP-current consumption plus investment for future consumption plus public goods consumption.

The second sum in 2 is related to variability of the quantities rather than the prices of different goods. It is reasonable to expect quantity and price variability to be related in a market-clearing economy, and thus the concern about relative price variability can be interpreted as an indirect interest in relative quantity variability.

To see more clearly how the two components of 2 are related to GNP and to measures of quantity variability, consider a special case. Suppose for simplicity that the utility function is constant elasticity of substitution in the form

$$
U(X)=\left(\sum_{1}^{N}\left(w_{i} X_{i}^{-\rho}\right)\right)^{-1 / \rho},
$$

where $\sigma=1 /(1+\rho)$ is the elasticity of substitution. Then the secondorder approximation 2 is equal to

where

$$
\frac{\Delta U}{U}=\sum_{1}^{N} \alpha_{i} \frac{\Delta X_{i}}{X_{i}}-\frac{1+\rho}{2} \sum_{1}^{N} \alpha_{i}\left[\left(\frac{\Delta X_{i}}{X_{i}}\right)-\sum_{1}^{N} \alpha_{i} \frac{\Delta X_{i}}{X_{i}}\right]^{2}
$$

$$
\alpha_{i}=\frac{w_{i} X_{i}^{-\rho}}{\sum_{1}^{N} w_{j} X_{j}^{-\rho}}, \Sigma \alpha_{i}=1 \text {. }
$$

In this case, the proportional change in welfare or utility can be evaluated from any initial position by looking first at a weighted sum of the growth rates of real quantities (the first term) and, second, adjusting for

38. Thomas Juster has pointed out that there is little empirical evidence that work produces disutility. 
variability of quantities (the second term). From the welfare viewpoint, given the utility represented by the first term, variability of quantities is a "bad." However, measures of quantity variations cannot indicate whether the variations result from optimal responses to shocks or from misperceptions or poor policy responses. The cost of a given amount of relative quantity variation increases as the elasticity of substitution falls. However, the lower the elasticity of substitution, the smaller is the amount of quantity variation to be expected for any specific shock.

There are two points to be made about the welfare economics of the effects of inflation and any other disturbances that affect the economy. The most important point is that the concern about relative quantity variability is a second-order concern. The measure of relative quantity variability, that is, the second sum on the right-hand side of equation 4 , averages 0.000118 . This is trivial compared to a 1 percent shortfall of the first term from its potential. ${ }^{39}$ This means that much more of the welfare effects of disturbances to the economy have been through changes in the level of GNP or consumption than through changes in the composition of consumption. Concern about the effects of disturbances on quantity variability is interesting, no doubt, but focuses on a measure of much smaller welfare significance than the growth in GNP. ${ }^{40} \mathrm{I}$ look briefly at the behavior of a measure of quantity variability before turning to the effects of disturbances on the growth rate of GNP, which is the first-order concern.

\section{VARIABILITY OF QUANTITIES}

Figure 5 contains two quantity variance measures constructed in the same way as the price variability measures earlier in the paper. The measure $V A R Q 11$ contains the eleven components of the consumption part of GNP described in the appendix. The measure $V A R Q 10$ excludes automobiles from $V A R Q 11$. It is clear from figure 5 that automobile strikes and the 1980 automobile production collapse dominate the behavior of $V A R Q 11$. Variability in the purchases of durables like automobiles should not receive the same weight in a welfare index that variability in nondurables receives.

39. From $1956: 1$ to $1980: 3$, the standard deviation of the quarterly growth rate of a weighted sum of the components of consumption in GNP was 0.00745 .

40. For very low elasticities of substitution the second term becomes important. For instance, if the elasticity of substitution is less than 0.01 , the two terms will be of approximately equal weight. 
Figure 5. Quantity Variability, Components of Consumption Expenditure, including $(V A R Q 11)$ and excluding $(V A R Q 10)$ Automobile Expenditure, 1948-80a

Standard deviation of relative quantity changes (percent per quarter)

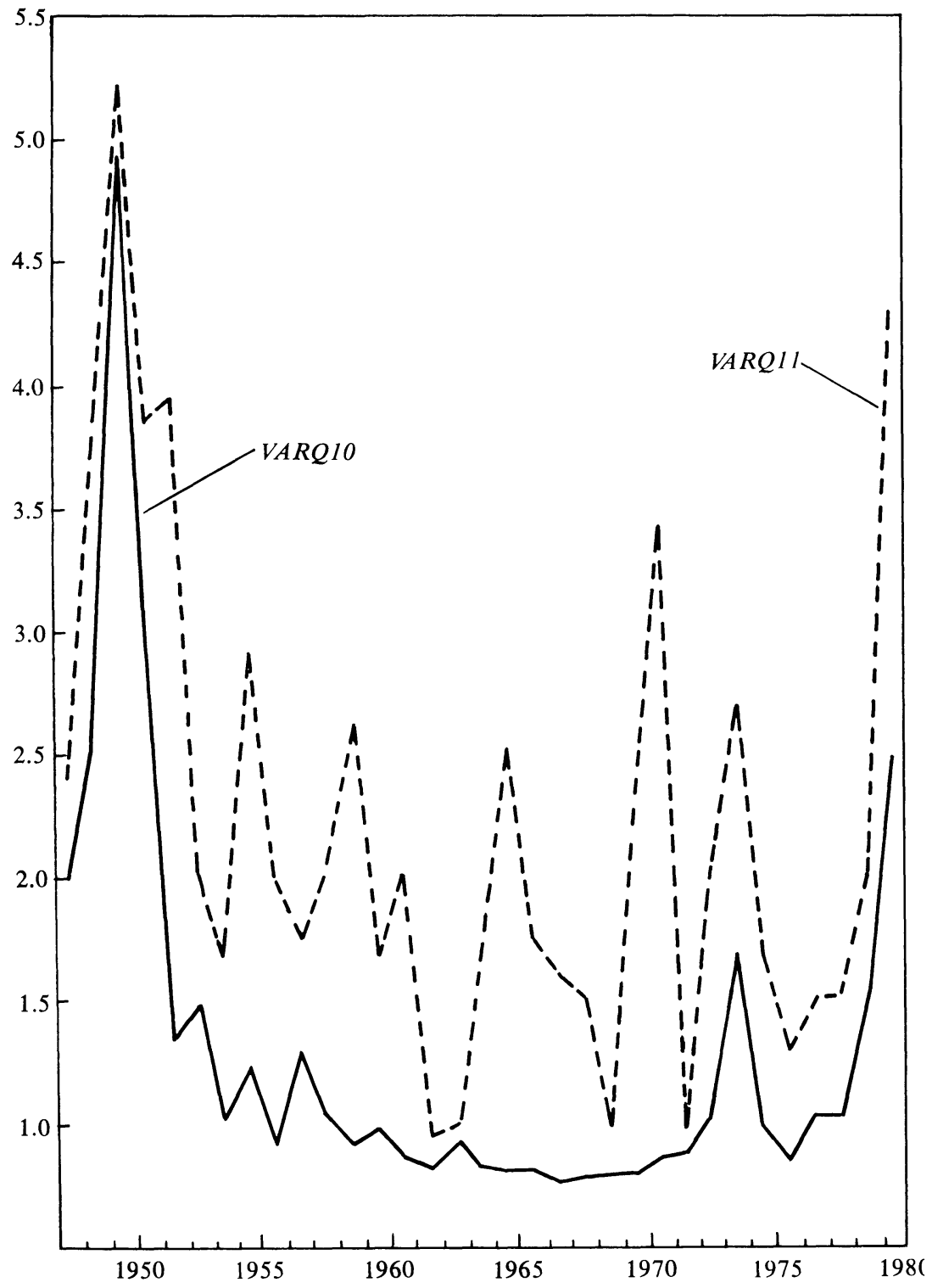

Source: Citibank Economic Database.

a. Data shown are standard deviation measures. The $V A R Q 10$ and $V A R Q 11$ for each quarter in a year are averaged, and the square root is then taken. The $V A R Q$ measures are based on quarter-to-quarter changes at quarterly rates. 
Comparing figures 1 and 5 suggests that relative price and relative quantity variability have been correlated. This is confirmed by regression 10-1 in table 10, which explains $V A R Q 10$. It is also quite clear that the correlation reflects the common impact of the oil and food shocks of the 1970s, for regression 10-2 in table 10 shows no relation between the two variability measures. Regressions not shown in the paper demonstrate that in neither period is there any significant association between the variability of quantities and the inflation rate.

\section{EFFECTS OF SHOCKS ON GNP}

I turn now to the effects of different shocks on the growth rate of GNP. Those shocks are taken to be the innovations in the eight-variable vector autoregressive system discussed above. Their effects are measured by what part of the variation of the growth rate of real GNP, the welfare indicator, can be attributed to each of the shocks.

The relevant results have already been presented in the variance decompositions of table 8 . These are repeated in table 11 , along with the results of the second ordering of the variables introduced in table 9, in which the Treasury bill rate and food and energy prices exchange places. To reduce detail, only the variance decompositions for eight periods are shown.

It is clear under either ordering that money supply and fiscal policy do not receive much of the credit or blame for the behavior of real GNP during the period; nor does the inflation rate or the variability of relative prices. Most of the credit given to variables other than GNP growth itself is divided among the Treasury bill rate, food prices, and energy prices. The proportions depend entirely on the ordering of the variables. When the Treasury bill rate is first in the ordering, it receives 27 percent of the credit for the variability of real GNP growth. Under both orderings, increases in the nominal Treasury bill rate sharply reduce GNP growth (see table 7). Pending an explanation of this relation, which has been studied by Litterman and Weiss, it is difficult to know whether to attribute the effects to anticipated policy changes reflected in Treasury bill rates or to another source. ${ }^{41}$ The different importance of the Treasury bill rate when it changes places in the ordering with food and energy prices highlights the difficulty in distinguishing the effects of innovation from these sources.

41. Litterman and Weiss, "Money, Real Interest Rates." 


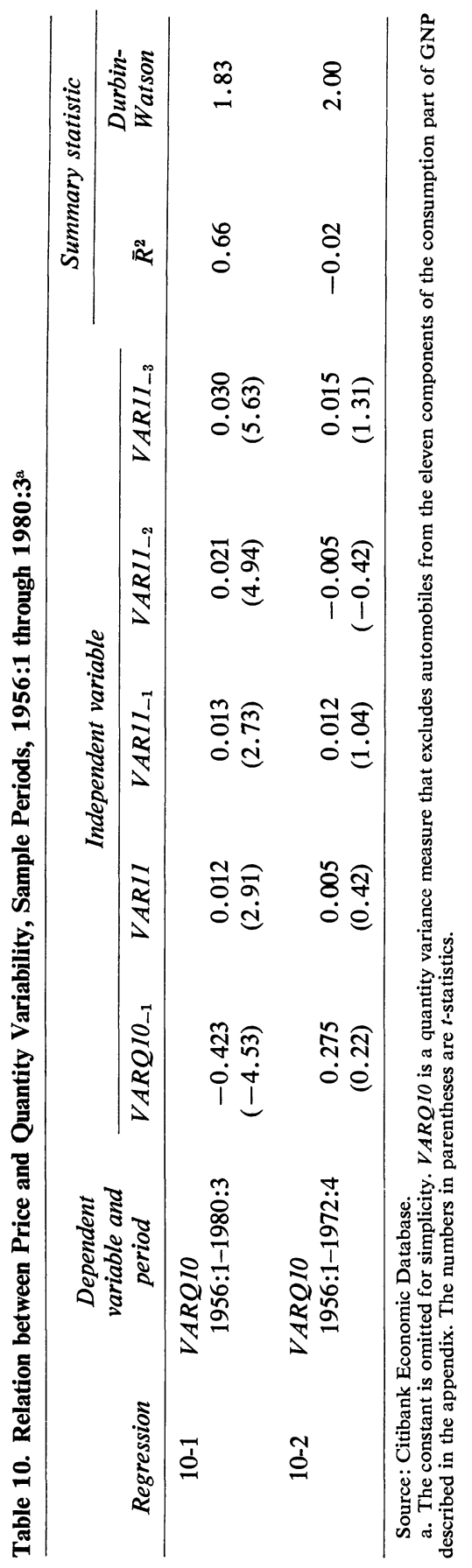




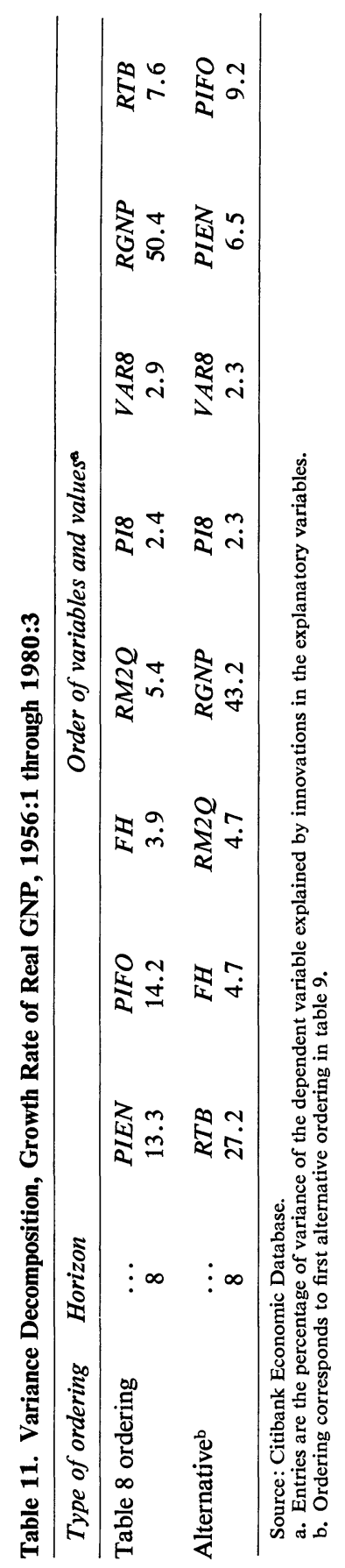




\section{International Comparisons}

The results of this paper tell a fairly simple story. The behavior of the measure of relative price variability over the $1956-80$ period is dominated by the food and energy price shocks of the 1970s. When food and energy prices are included in the measure of relative price variability, that measure appears to have major macroeconomic significance and to be strongly associated with the behavior of the inflation rate. When those prices are separated from that measure, relative price variability no longer has major macroeconomic significance. In particular, relative price variability does not significantly affect the growth rate of real GNP.

It was noted above that the vector autoregressive approach does not permit discussion of the effects of alternative policy reaction to disturbances and that for this reason it would be desirable to examine the role of relative price variability in other economies. Below I briefly present comparative results for Germany and Japan.

\section{DOMINANCE OF FOOD AND ENERGY SHOCKS \\ IN THE 1970s}

Figures 6 and 7 indicate that food and energy price shocks dominate the behavior of relative prices for Germany and Japan, respectively, just as they do for the United States. These two figures can be compared with figure 2 .

\section{ROLE OF POLICY AND RELATIVE PRICE SHOCKS}

In the case of Germany there is a weak correlation between the inflation rate and relative price variability on a quarterly basis. In a vector autoregressive system for Germany estimated from 1969:1 to 1980:2, the variability of relative prices accounts at most for less than 10 percent of the variance of the inflation rate-even when the variability of relative prices is placed first in the ordering of variables and when food and energy prices are retained in the variability index..$^{42}$ Furthermore, there is very little role for the variability of relative prices as a macroeconomic vari-

42. Detailed results are presented in Fischer, "Relative Price Variability and Inflation." 
Figure 6. Relative Price Variability in Germany, Measures including (VARG8) and excluding (VARG5) Food and Energy Prices, 1969-79a

Variance of relative price change

(percent per quarter, squared)

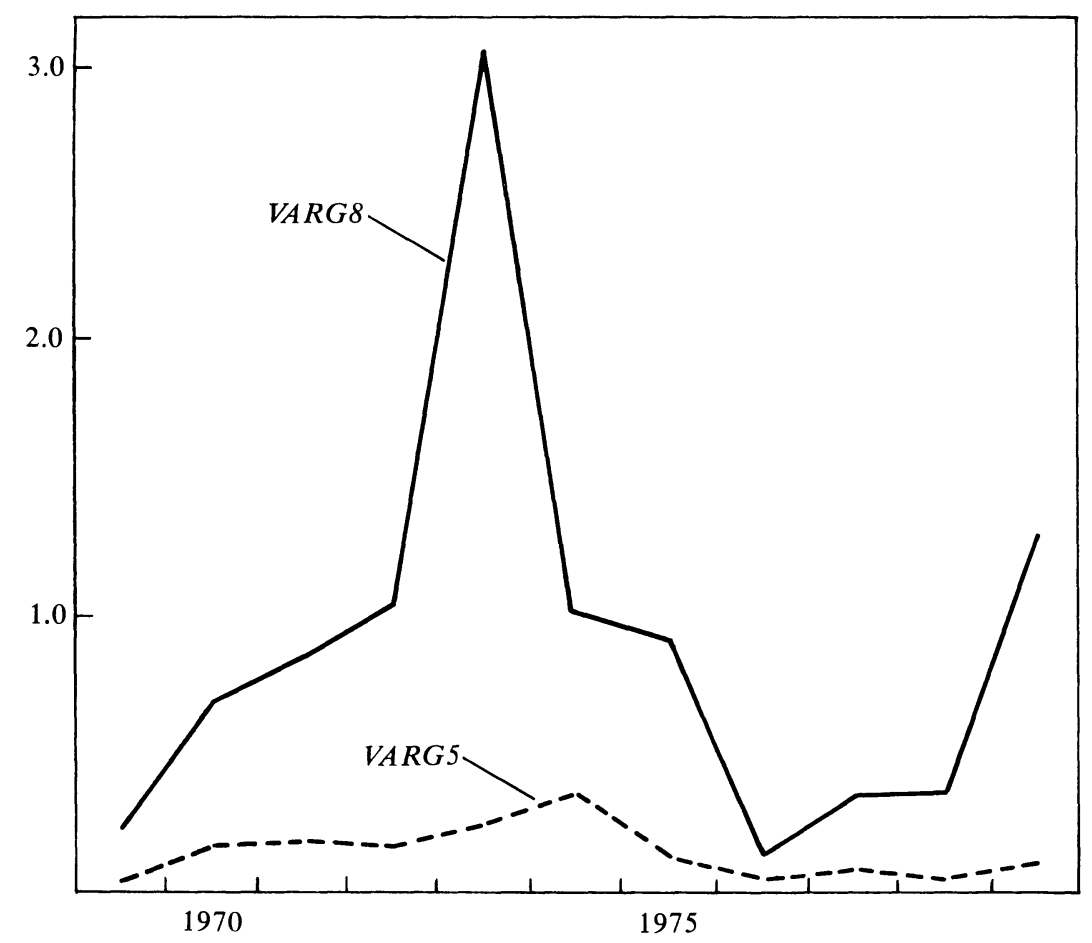

Source: Citibank Economic Database.

a. Measures are annual averages of variances of quarter-to-quarter inflation rates of consumer prices, at quarterly rates. There are eight components in VARG8. The three components omitted in VARG5 are electricity, gas, and gasoline; food and beverages; and transportation and communication.

able, again even when food and energy prices are retained in the index. Examination of monetary policy responses in Germany shown by the IRFs suggest the difference in the response of German inflation and other macroeconomic variables to changes in relative prices arises from the nonaccommodative German monetary policy.

In a five-variable vector autoregressive system for Japan estimated from 1971:2 to $1979: 4$, it is difficult to disentangle the effects of relative price variability from those of inflation. Because Japanese inflation peaked strongly in 1973 and 1974, when relative price change was most rapid, the data are not capable of distinguishing the effects of relative price variability from those of inflation. Because of a lack of degrees of freedom, 
Figure 7. Relative Price Variability in Japan, Measures including $(V A R 17)$ and excluding (VAR13) Food and Energy Prices, 1953-80a

Variance of relative price change (percent per month, squared)



Source: Citibank Economic Database.

a. Measures are annual averages of variances of month-to-month inflation rates for components of the wholesale price index, at monthly rates. There are seventeen components in $V A R I 7$. The four components omitted from $V A R 17$ in calculating $V A R 13$ are electricity and power, chemicals, foodstuffs, and petroleum and coal products.

it was not possible to operate with a larger system in which food and energy prices were treated separately to see if effects attributed to relative price variability should be attributed instead to the changes in relative food and energy prices in 1973 and 1974. The data in figure 7 do strongly suggest, though, that Japanese relative price variability in this period was dominated by changes in food and energy prices, which makes it likely that similar conclusions would be reached for Japan as for the United States if longer time series were used.

One other aspect of Japanese relative price variability and inflation interrelations is important in illustrating the role of policy. At the beginning of the first oil shock, Japan was essentially running an accommoda- 
tive monetary policy. The first energy shock therefore shows up clearly in Japanese inflation. By 1979-80, however, Japan had converted to nonaccommodation, and the second energy shock hardly shows up in Japanese inflation.

This brief examination of the experience of two foreign countries therefore supports two points. First, energy and food price shocks indeed dominate the behavior of indexes of relative price variability in the $1970 \mathrm{~s}$. Second, the association between inflation and relative price variability is not immutable and may depend on the nature of monetary policy. Nonaccommodative monetary policy can moderate the effects of relative price changes on the inflation rate.

\section{Concluding Comments}

Three conclusions are supported by the findings of this paper. First, the association between relative price variability and inflation in the post1956 period in the United States is dominated by food and energy shocks. Second, even after removing the effects of these shocks, monetary shocks or unanticipated changes in money or in interest rates are associated with increased relative price variability. Third, from a welfare economics viewpoint, relative price variability is at best an indirect measure of welfare. To examine the effects of shocks-for instance, monetary shocks-on welfare, it is more useful to work with GNP than with relative price variability. There is little evidence that policy shocks in the United States played an important role in the poor macroeconomic performance of the 1970s.

Two other points deserve emphasis. First, the relation between inflation and relative price variability can arise from many sources. The fact that the relation was dominated by relative price shocks in the 1970 s does not mean that will always be true. Over a longer time period, other shocks such as the depression and World War II have had important effects on both inflation and relative prices. Second, the relation between relative price variability and inflation, and between these and other variables is not independent of policy. The techniques used in this paper do not address the question of the optimal policy response to shocks or the question of whether different U.S. policy in the 1970s might not have changed macroeconomic performance, for better or worse. 
A P P E NDIX

Components of the Deflators

Eight variables

Automobiles

Furniture

Other durables

Clothing

Housing

Household operation

Transportation

Other services

\section{Eleven variables}

Automobiles

Furniture

Other durables

Clothing

Food

Gasoline

Fuel oil, coal, and other nondurables

Housing

Household operation

Transportation

Other services

Twelve variables

Automobiles

Furniture
Other durables

Clothing

Food

Gasoline

Fuel oil and coal

Other nondurables

Housing

Household operation

Transportation

Other services

\section{Sixteen variables}

Automobiles

Furniture

Clothing

Food

Gasoline

Fuel oil and coal

Other nondurables

Housing

Household operation

Transportation

Other services

Nonresidential structures

Nonresidential producers' durables

Residential nonfarm structures

Residential farm structures

Residential producers' durables 


\section{Comments and Discussion}

Robert E. Hall: Mainstream economists are united in the view that inflation is bad. Only a radical fringe questions this orthodoxy. In this paper, Stanley Fischer examines one of the central arguments against inflation: by distorting relative prices, inflation interferes with efficient resource allocation. Part of the argument rests on evidence that episodes of higher inflation have also had greater variability of relative prices.

One of the paper's important advances over earlier literature in this area is its recognition that inflation is an outcome of economic processes, not an exogenous causal influence. Fischer's first contribution is to sort out what one might mean in saying that greater variability of relative prices is a cost of inflation. He gives us a list, which I will summarize, though not in his order, as a way of organizing some of my remarks.

First, misperceived disturbances cause inappropriate relative prices and misallocation of resources. The misperceptions hypothesis has no implications for inflation itself-misperceived monetary shifts in either direction are costly. Minimization of these costs does not involve ending inflation, but rather publishing all available monetary data at $4 \mathrm{pm}$ every Friday. Because ending inflation would probably create some misperceptions, a better policy is to stabilize inflation at its current rate, according to the misperceptions view.

Second, changes in macro policy change the rate of inflation and relative prices at the same time. The shifts in relative prices are simply the efficient operation of the economy and are not in any sense a cost of inflation.

Third, because costs of changing prices vary by product, higher overall rates of inflation may bring more dispersion in relative prices. Although this type of dispersion does carry inefficiency with it, it is hard 
to believe that the costs amount to anything at rates of inflation below 20 percent a year. Many tricks are available to merchants to minimize the costs of changing prices. For example, at the Harvard Coop, the prices of records are marked as A, B, C, . . A sign at the checkout counter translates these into dollar prices.

Fourth, supply shocks influence both overall prices and relative prices. Again, the movements in relative prices are the efficient working of the system and are not a cost of inflation. In postwar U.S. history, supply shifts appear to be the dominant cause of the association between inflation and variability in relative prices.

Fifth, Phillips curves in individual markets are curves, not lines. A steeper Phillips curve means a market is working better. With higher average inflation, the typical market is at a steeper point on its Phillips curve and so is functioning more efficiently. Inflation is good, not bad, because it helps achieve desirable shifts in relative prices.

Sixth, monetary policy may be more expansionary when events occur that shift relative prices. Once again, inflation cannot be said to cause misallocation of resources.

After giving the reader this useful list, Fischer plunges into empirical work, but it is worth pausing and asking whether anything is left of the idea that increased variability of relative prices is a cost of inflation according to any of these views. Only the misperceptions hypothesis squarely associates distorted relative prices with costs of inflation. But it has two interpretations, neither of which supports any benefits from decreased inflation: (1) all the Federal Reserve has to do is announce everything it knows about the money stock to bring misperceptions to an irreducible minimum or (2) prediction errors matter for some reason, and we need to keep the money stock on its previously expected track. The first says we can do whatever we like with the money stock and the price level, as long as we are open about it. The second suggests we should maintain inflation at about its current level. Thus Fischer has disposed of the last item in his list offering any hope of supporting a connection between efficient allocation of resources and inflation.

Fischer continues rather than wrapping the paper up at this point because there are interesting scientific questions to settle, even if the conclusions about policy are foregone.

The simple history of inflation and relative price variability conveys the basic message of the paper: the two are correlated, and wars and 
food-energy shocks are the source of the correlation. The closest thing there is to a pure experiment in sustained inflation without these sources was the period from 1965 to 1972 , when variability was at extraordinarily low levels. Fischer's extensive examination of the relation between inflation, relative price variability, and other macro variables pins the point down fairly conclusively. Changes in relative prices have not been a universal partner of inflation, but have come from global weather and the activities of the oil cartel.

Toward the end of the paper Fischer asks a question he might logically have asked much earlier: even supposing that inflation brought distortions in relative prices, what are the ensuing welfare costs? His results strongly confirm James Tobin's famous remark that it takes a thousand Harberger triangles to fill one Okun gap. If the benefits of ending inflation are measured by the tiny number found by Fischer, and if the Phillips curve literature is anywhere near the mark on the cost of ending inflation, then tolerating inflation is clearly the preferable alternative.

I see two principal conclusions from the paper with respect to macro policy. First, the motivation for ending inflation cannot be elimination of excess variability of relative prices. Variability has indeed been higher in times of inflation, but for good microeconomic reasons. Second, all the findings suggest that anti-inflation policy-at least monetary restriction and high interest rates-has adverse effects on real output. There is no hint of any magical policy giving price stability without an intervening recession.

In view of these two conclusions, it seems to me that policy should aim to phase out inflation slowly, at perhaps 1 percent a year. Rapid disinflation threatens all the other accomplishments of current economic policy-improved incentives, rapid real growth, and a trimmed government.

John B. Taylor: Stanley Fischer's paper is an important contribution to the growing literature on the relation between inflation and relative price variability. His systematic survey of the theoretical arguments is successful in giving order to a confusing array of theories that have been put forth to explain the correlation. His extensive empirical investigation shows that the simple bivariate correlation between inflation and relative price variability diminishes significantly in an appropriate multivariate setting in which intermediating effects can be controlled. 
The most striking of Fischer's empirical findings - as well as the most convincing, in my view-is that the relation between inflation and relative price variability since the mid-1950s is dominated by the energy and food supply disturbances that simultaneously affected both variables. The most direct evidence in support of this view is provided in figure 2 of his paper. The correlation between the level of inflation and relative price variability, so evident in this figure, largely disappears when energy and food prices are omitted from the index. Further support for the view can be found in the regression and autoregression results, but the figures are most convincing because they provide the information that the main movements in the variables occurred at the same time as well-documented supply shocks (that is, shifts in energy and food supply curves). This timing is not evident in the regression or autoregression statistics. It is very difficult to look at these figures without becoming convinced that the large supply shifts in energy and food in the 1970s were at least the initial force behind the nearly simultaneous movements in inflation and relative price variability that occurred.

A second result of the empirical investigation emphasized by Fischer is that monetary shocks are correlated with relative price variability and therefore have some role to play in explaining the relation, after one has accounted for supply factors. However, the role of monetary shocks is minor compared to the role played by supply shocks, and fiscal policy shocks are even less important. These policy shock results are based entirely on the autoregression statistics provided by the autoregressive timeseries methodology employed by Fischer in his analysis. Since policy variables are being used in this analysis, one might suppose that the results have policy implications. In my view, such a supposition would be entirely incorrect.

Although the vector autoregressive methodology has the advantage of not being dependent on particular economic theories, it has the disadvantage of not permitting one to draw any policy implications, unless some structural interpretations are made. The difficulty comes in giving policy interpretations to the autoregressive statistics. At best, these results can be interpreted as estimates of the effect of monetary policy shocks-unanticipated and temporary deviations from the monetary policy process such as might be caused, for example, by a mistake in estimating the money supply. But even the interpretation of the results in terms of policy shocks or disturbances requires a structural interpreta- 
tion, for in general these shocks are combinations of shocks to all relations in the economic system. Moreover, the methodology cannot evaluate the effect of a change in the systematic part of monetary policy. This disadvantage seems particularly troublesome for the analysis of the relation between inflation and relative price variability in the 1970s, in which one is interested in whether different policies (say, less accommodative policies) would have altered the behavior of these variables. Fischer deals with this problem at the end of his paper by reporting the results from an intriguing international comparison of Germany, Japan, and the United States. He finds that relative price shocks pass through the economic system with comparatively little impact on inflation in Germany. According to his analysis, Germany appears to have followed a less accommodative monetary policy than the United States. In other words, systematic monetary policy defined in terms of the degree of accommodation seems to have a major effect on the relation between relative price variability and inflation. In my view, these policy implications are correct. However, even with these international data, it should be emphasized that Fischer must give a structural interpretation to the vector autoregressive results in order to derive these policy implications: he must assume that the money equations in the vector autoregressive systems can be interpreted as structural monetary policy functions. Without such a structural interpretation, the system responses cannot be attributed to "nonaccommodative" German monetary policy.

It is useful to introduce some traditional econometric terminology in order to be more precise about the difficulties in interpreting vector autoregression statistics. Fischer's autoregressive equation system in which each of the six (or eight) variables are regressed on the lagged values of all variables in the system can be interpreted as a reduced form of a structural, simultaneous equation econometric model. The essential characteristic of the structural model in this context is the presence of current values of more than one variable in each equation. The reduced-form autoregression is the solution of this simultaneous system in which only one current period variable appears in each equation. The structural econometric model would not have unexplained exogenous variables, but it would have lagged variables, just as the autoregression does. Policy instruments, for example, frequently treated as exogenous in econometric models, would be explained by policy functions that would be part of the structural system and would show how policy variables react to current 
and lagged values of other variables in the system. The money-supply equation, for example, might show a monetary response to the current level of GNP and the current level of inflation to capture the monetary authority's typical actions. If policy reacted slowly, it would be necessary to have lagged values of these variables in the equation. Because both the structural econometric model and its reduced form both have lagged variables, the autoregressive terminology really applies to both. We have a structural autoregression versus a reduced-form autoregression.

In moving from a structural autoregression to the reduced-form autoregression, two important transformations take place that make interpretation of the latter difficult. First, the coefficient of the lagged dependent variables in the structural autoregression get scrambled: the coefficients of each lagged variable in the reduced-form autoregression become functions of many of the structural form parameters. For example, the coefficients of lagged GNP and lagged inflation in the money-supply equation are no longer pure policy response coefficients. To identify these coefficients one needs to take some stand on the form of the structural model. Without this, the policy response coefficients remain hidden in the reduced-form autoregression, and it is impossible to interpret the impact of a more responsive or less responsive policy.

The second important transformation is that of the disturbances to the relations. The disturbances of a structural autoregressive model can be interpreted as shifts in the structural relations. For example, such a disturbance would represent a shift in the supply curve rather than a movement along it. These disturbances can be correlated between the different relations of the structural model without changing this interpretation. Shifts in supply and demand curves could be correlated. In moving to the reduced-form autoregression, however, these structural disturbances become mixed together so that the disturbances to each reduced-form equation are combinations of disturbances from all the structural equations. This is why it is impossible to interpret the estimated disturbances to the reduced-form relation as supply shocks or monetary policy shocks, without imposing some specific structure on the model. This structure is necessary whether or not the reduced-form disturbances are correlated.

This mixing together of disturbances also has implications for the impulse response function estimates discussed by Fischer and used for inferences about the relative importance of monetary and other shocks. Without a structural interpretation, it is arbitrary how one untangles 
the reduced-form disturbances in calculating these response functions. Fischer indicates that it would be possible to calculate the impulse responses to each individual reduced-form disturbance and argues that this is not unlike what is done in simple regression analysis. In my view, there is some appeal to this approach, for then the impulse response function is a simple transformation of the reduced-form autoregressive coefficients. Instead, however, Fischer uses the ordering procedures suggested by Christopher Sims. Because the ordering procedure is arbitrary, Fischer experiments with some alternative ordering schemes. The results are reported in table 9 of the paper and do show some sensitivity to the form of ordering used. It should be clear from this discussion, however, that even experimenting with all alternative ordering combinations of the type reported in table 9 would not exhaust all the possible ways to untangle the reduced-form disturbances.

Much of my discussion has focused on the autoregressive methodology used by Fischer because many of his conclusions are based on this methodology. The questions I have raised about the methodology mainly relate to the need to use some structural economic theory or other auxiliary information if the results of the vector autoregressive methods are to have substantive economic implications. In an important way Fischer's paper shows how such implications can be drawn out of the autoregression statistics. By using structural interpretations to assess the relative degree of monetary accommodation in Germany, Japan, and the United States, he is able to draw a policy implication about the impact of monetary policy in reducing the relation between inflation and relative price variability.

\section{General Discussion}

Lawrence Summers and Robin Marris observed that Fischer does not consider some types of relative price changes that are likely to be important to allocation and distribution. Summers stated that the real interest rate is one of the economy's most fundamental prices since it determines the rate at which present consumption can be traded off for future consumption. Because of the high correlation between inflation and the variability of inflation through time, the real interest rate is also likely to be variable during periods of high inflation. The variability of real interest 
rates could in turn affect relative prices of durable goods-which are capital assets-in comparison to nondurable goods. Furthermore, the variability of the real interest rate would be expected to affect the volatility of exchange rates, thus altering the relative prices of goods that are internationally traded and those that are not. Fischer acknowledged that inflation might induce uncertainty about real interest rates but pointed out that relative price effects on durable goods should be captured in his price series. Marris pointed out that two other kinds of prices that may be of special importance have been excluded from consideration-the prices of different types of labor and different forms of wealth. If high inflation were associated with great uncertainty about these relative prices, then individuals would suffer considerable anxiety regarding the future of their own real incomes with a consequent decline in real welfare. With respect to the larger message of the paper, Marris mentioned that in his own cross-country research the relation between inflation and growth, if it exists, is extremely tenuous, with a slight suggestion of a negative relation between the two.

There was extensive discussion of how to interpret some of the statistical results. Christopher Sims pointed out that the evidence from the vector autoregressions regarding the impact of money innovations on price variability is ambiguous. Money innovations could appear "causal" even if the money stock were itself passive but very closely connected to other financial variables, such as interest rates, that were themselves causal or forward looking. Similarly, he argued that relative price variability itself might appear causal when it is not, simply because of the forwardlooking behavior of the prices of durable and storable commodities whose prices are set in auction markets. He agreed with Fischer's caution in drawing policy conclusions from his results. George Perry observed that it is equally difficult to draw policy inferences from the results briefly reported for Germany and Japan. Fischer interprets their experience with OPEC-2 as evidence that a nonaccommodative policy can avoid inflation. However, the importance of government-industry-labor-bank cooperation, or even coercion, is never explored, although many observers give these relations, working in tandem with macroeconomic policies, much of the credit for controlling inflation in both countries. In Fischer's vector autoregressions any contribution from such policies would be credited to other variables such as the money stock. Furthermore, Perry observed that there are substantial shortfalls of output below trend in both coun- 
tries, but these are not discussed as they are in Fischer's analysis for the United States.

Stephen Goldfeld questioned whether monetary and fiscal policy could be properly characterized by the variables Fischer used. The normalized full employment surplus is an imperfect measure of fiscal policy and the money supply is an endogenous variable rather than a Federal Reserve target for much of the period being studied. Thus variations in the money supply cannot be identified as innovations in monetary policy.

James Tobin reported findings from the doctoral dissertation of David Stockton, which generally confirm Fischer's results, even though based on ninety-one components of the producer price index rather than the smaller number of relative prices examined by Fischer. Tobin interpreted Stockton's dissertation to show that relative price variability arising from micro shocks, like food and energy, have been much more important than the variability arising from macro policy shocks over the postwar period. The correspondence of Stockton's and Fischer's results, despite different data and methodologies, gave Tobin greater confidence in their results.

Much discussion centered on the broader implications of Fischer's results. Alan Blinder questioned how much one could learn from the type of vector autoregressions used in the paper. In accounting for GNP fluctuations, for example, the estimates only reveal the impacts of variables after taking account of changes in GNP that could be predicted by several lagged values of GNP itself. The underlying relation that causes GNP to be so well predicted by its own past values is not clarified. Robert Gordon disagreed with this interpretation. He reasoned that the high dependence of GNP on its own past values shows that fluctuations arise mainly from the multiplier-accelerator process, rather than coming mainly from decisions made in the Federal Reserve. Indeed, the results show the money supply has a very limited effect on GNP and inflation once inertia and the impact of energy and food shocks are accounted for.

Sims disagreed with the comment of Robert Hall that the welfare costs of misperception can be dismissed without serious empirical investigation. Sims argued that the frequent publication of money supply or price data does not, by itself, eliminate the possibility that misperceptions are an important source of welfare loss. Invisible barriers to rapid information flow or obstacles to rapid revisions in nominal contracts are usually characterized, in a stylized way, as information delays. These deserve to be taken seriously. Sims did agree that the results in the paper showing the 
large impacts of the oil and food price shocks in recent periods are difficult to reconcile with the view that attributes inflation mainly to monetary policy. Furthermore, he found it hard to reconcile the fact that the connection between relative price variability and inflation has a very different detailed structure in different historical periods with the view that the connection reflects monetary shocks working through frictions, delays, and misperceptions. 